INTERNATIONAL JOURNAL
OFICAL SCIENCES
PHARMACEUTICAL
RESEARCH

Received on 01 May 2020; received in revised form, 10 October 2020; accepted, 12 April 2021; published 01 May 2021

\title{
PYRAZOLINE HETEROCYCLIC: A REVIEW
}

\author{
Biswajit Dash and Shajidul Karim *
}

Department of Pharmaceutical Analysis \& Quality Assurance, Himalayan Pharmacy Institute, Majhitar 737136, East Sikkim, India.

\section{Keywords:}

Pharmaceutical chemistry, Radiopharmaceuticals, Antiinflammatory, Heterocyclic compound, COX-2 inhibitor

\section{Correspondence to Author:}

Shajidul Karim

M. Pharm,

Department of Pharmaceutical Analysis \& Quality Assurance, Himalayan Pharmacy Institute, Majhitar - 737136, East Sikkim, India.

E-mail: shajidulkarim451@gmail.com

\begin{abstract}
Pharmaceutical chemistry is devoted to the discovery and development of new agents for treating diseases. Inorganic compound continues to be important in therapy, for example, as antacids, mineral supplements, and radiopharmaceuticals, but organic molecules with increasingly specific pharmacological activities are clearly dominant. The five and six-membered heterocyclic nitrogen-containing systems such as pyrazole, imidazole, trizoles, thiozolidine, pyrazolidine, etc., are far by the most important in the ongoing research for more efficacious drugs in the fields such as anti-bacterial, fungicidal, anti-inflammatory, anticonvulsant, diuretics, and anti-histaminic, etc. Pyrazoline is a five-membered heterocyclic compound having two adjacent nitrogen atoms within the ring. It has only one endocyclic double bond and is basic in nature. Pyrazole derivatives have a long history of application in agrochemicals and pharmaceutical industry as herbicides and active pharmaceuticals. The recent success of pyrazole COX-2 inhibitors has further highlighted the importance of these heterocyclic rings in medicinal chemistry. Many scientists have synthesized novel pyrazoline derivatives. They have characterized the synthesized compounds by thin-layer chromatographic technique and analyzed the spectrum by IR, NMR, Mass spectra. Some compounds had been synthesized by the microwave method of synthesis, which is more convenient than the normal method of synthesis. Pyrazoline is a unique template that is associated with several biological activities. This literature high lightened research work of many researchers reported in literature for different pharmacological activities on pyrazole and pyrazoline compounds synthesized.
\end{abstract}

INTRODUCTION: Pharmaceutical chemistry is devoted to the discovery and development of new agents for treating diseases. Inorganic compound continues to be important in therapy, for example, as antacids, mineral supplements, and radiopharmaceuticals, but organic molecules within caressingly specific pharmacological activities are clearly dominant.

\begin{tabular}{|c|c|}
\hline \multirow[t]{2}{*}{$\begin{array}{l}\text { QUICK RESPONSE CODE } \\
\text { (a) }\end{array}$} & $\begin{array}{c}\text { DOI: } \\
\text { 10.13040/IJPSR.0975-8232.12(5).2570-88 }\end{array}$ \\
\hline & $\begin{array}{l}\text { This article can be accessed online on } \\
\text { www.ijpsr.com }\end{array}$ \\
\hline DOI link: http:/ & $13040 /$ IJPSR.0975-8232.12(5).2570-88 \\
\hline
\end{tabular}

The objective of medicinal chemistry is the design and production of compounds that can be used as medicine for the prevention, treatment, and cure of humans or animal diseases.

It is concerned with the invention, discovery, design, identification of biologically active compounds, the study of their pharmacokinetic and pharmacodynamic profiles, interpretation of their mode of action at the molecular level and the construction of structure-activity relationship (SAR), the relationship between chemical structure and pharmacological activity for a series of compounds. The five and six-membered heterocyclic nitrogen-containing systems such as pyrazole, imidazole, trizoles, thiozolidine, pyrazoli- 
dine, etc., are far by the most important in the ongoing research for more efficacious drugs in the fields such as anti-bacterials, fungicidal, antiinflammatory, anticonvulsant, diuretics, and antihistaminic, etc.

Pyrazole: The term Pyrazole was given by Ludwig Knorr in 1883. Pyrazole Fig. 1 refers to the class of simple aromatic ring organic compounds of the heterocyclic series characterized by a 5-membered ring structure composed of three carbon atoms and two nitrogen atoms in adjacent positions. Being so composed and having pharmacological effects on humans, they are classified as alkaloids, although they are rare in nature. In 1959, the first natural pyrazole, 1-pyrazolyl-alanine, was isolated from seeds of watermelons.

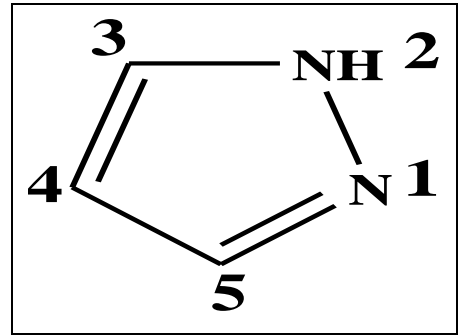

FIG. 1: PYRAZOLE

Pyrazole derivatives have a long history of application in agrochemicals and pharmaceutical industry as herbicides and active pharmaceuticals. The recent success of pyrazole COX-2 inhibitors has further highlighted the importance of these heterocyclic rings in medicinal chemistry. A systematic investigation of this class of heterocyclic lead revealed that pyrazole-containing pharmacy active agents play an important role in medicinal chemistry. The prevalence of pyrazole cores in biologically active molecules has stimulated the need for elegant and efficient ways to make these heterocyclic lead ${ }^{1}$.

Pyrazoline: Pyrazoline is a five-membered heterocyclic compound having two adjacent nitrogen atoms within the ring. It has only one endocyclic double bond and is basic in nature. Among its various derivatives, 2-pyrazolines seem to be the most frequently studied pyrazoline type compounds. 2-Pyrazolines can be considered as a cyclic hydrazine moiety. From the X-ray study, it has been found that the structure of the fivemembered dihydropyrazole ring has an envelope conformation.
C5 atom is deviated from the almost planar system of the other four atoms of the heterocyclic ring. It plays a crucial role in the development of theory in heterocyclic chemistry and is also extensively used as useful synthons in organic synthesis $2,3,4$.

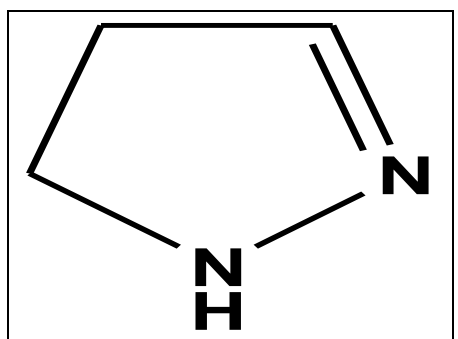

FIG. 2: PYRAZOLINE

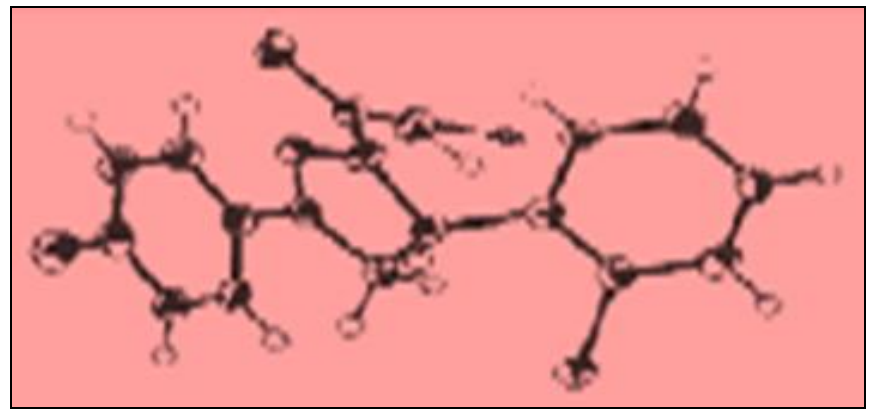

FIG. 3: SINGLE CRYSTAL X-RAY STRUCTURE OF1CARBOXAMIDO-2-PYRAZOLINE

Physico-chemical Properties: 2-pyrazoline is insoluble in water but soluble in propylene glycol because of its lipophilic character ${ }^{3}$. It is known that the compounds of the 2-pyrazoline group that do not contain a substituent at the 1-position of the heterocyclic ring can react with benzaldehyde at high temperature $\left(200{ }^{\circ} \mathrm{C}\right)$ and in an inert atmosphere to give 4-benzylidine derivatives. Pyrazoline derivatives, typical ICT (Intramolecular Charge Transfer) compounds, are known as a kind of fluorescent brightening agent because they have strong blue fluorescence in solution. They have a whole transport tendency. An intramolecular conjugated charge transfer process has been reported to exist in it in the excited state. In the conjugated part $(-\mathrm{N} 1-\mathrm{N} 2-\mathrm{C} 3-)$ of the ring, the nitrogen atom at the 1-position and the carbon atom at the 3-position are, respectively, electrondonating and withdrawing moieties. The carbon atoms at 4- and 5-positions do not conjugate with the above-conjugated part. Its fluorescence spectrum exhibits a large redshift with an increase in the polarity of solvents. These compounds show stronger fluorescence because of the double bond hindering, which occurred due to cyclization. 
Bulky groups in both the 4- and 5-positions improved both the fluorescence efficiency and the stability to the light of the molecule. It has significance for the design of pyrazoline whitening agents. Aryl group at position-5 is also responsible for spiroconjugated charge transfer quenching of pyrazoline fluorescence ${ }^{5,6,7,8}$.

Spectrum of Activity: 2-Pyrazolines display a broad spectrum of potential pharmacological activities and are present in a number of pharmacologically active molecules such as phenazone/amidopyrene/methampyrone (analgesic and antipyretic), azolid / tandearil (antiinflammatory), indoxacarb (insecticidal), anturane (uricosuric), etc. Considerable interest has been focused on the pyrazoline structure. The discovery of this class of drugs provides an outstanding case history of modern drug development and also points out the unpredictability of pharmacological activity from structural modification of a prototype drug molecule.

It is having a variety of medicinal applications 9,10 , 11, 12. Pyrazoline derivatives were found to have potential antipyretic analgesic, tranquillizing, muscle relaxant, psycho analeptic, antiepileptic, anti-depressant, anti-inflammatory, insecticidal, and antimicrobial and anti-hypertensive activities. Their derivatives were also found to exhibit cytotoxic activity, the inhibitory activity of platelet aggregation, herbicidal activity, and cannabinoid CB1-receptor modulators. They also possess some potent receptor-selective biological activity like Nitric oxide synthase (NOS) Inhibitors. Pyrazoline interest extended to dyes and dye couplers to ${ }^{13,14}$.

\section{Literature Review:}

Chemical Review: 2-pyrazoline is stable because it does not lose nitrogen as easily. The nitrogen present in the ring has 2 lone pairs of electrons. So, it acts as an electron donor group.

\section{General Method of Preparation of Pyrazoline:}

Method-1: 1, 3-Diketones, which were synthesized in situ from ketones and acid chlorides, were converted into pyrazoles by the addition of hydrazine.

This method allows a fast and general synthesis of previously inaccessible pyrazoles and synthetically demanding pyrazole-containing fused rings ${ }^{15}$.

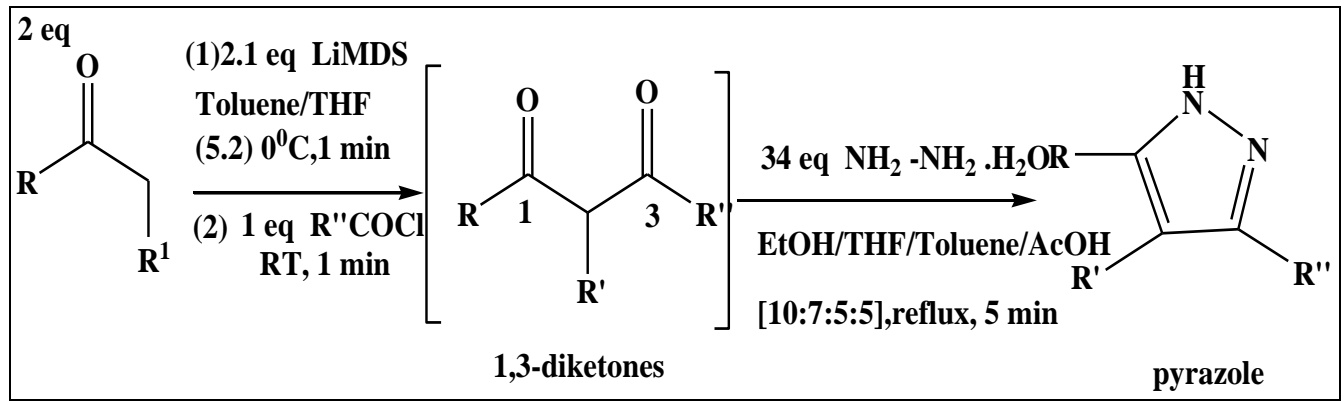

Method-2: A highly regioselective synthesis of 1- proceeds at room temperature in N,Naryl-3,4,5-substituted pyrazoles based on the dimethylacetamide and furnish espyrazoles in good condensation of 1,3-diketones with arylhydrazines yields ${ }^{1}$.

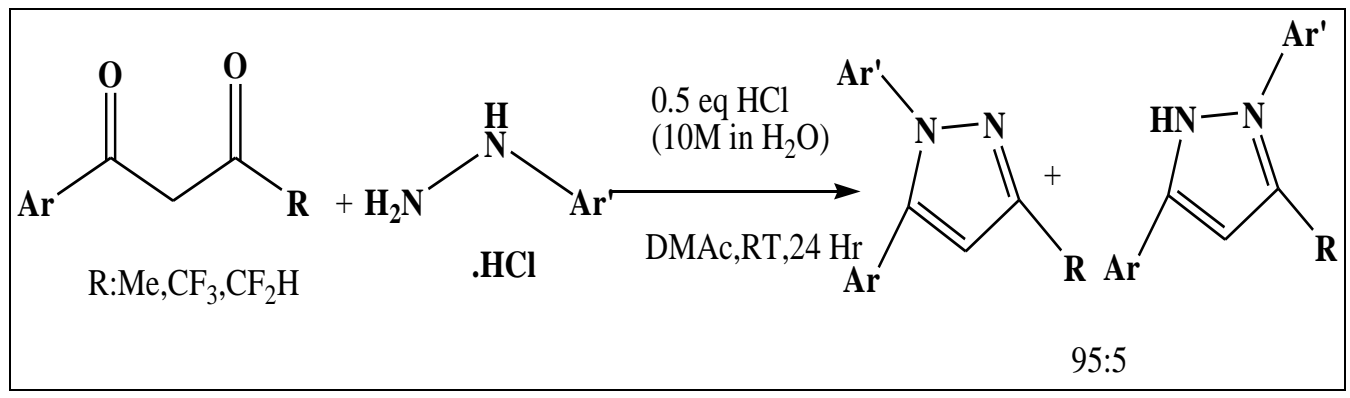

Method-3: Pyrazole or isoxazole derivatives are prepared by a palladium-catalyzed four-component coupling of a terminal alkyne, hydrazine (hydro- xylamine), carbon monoxide under ambient pressure, and an aryl iodide ${ }^{17}$. 


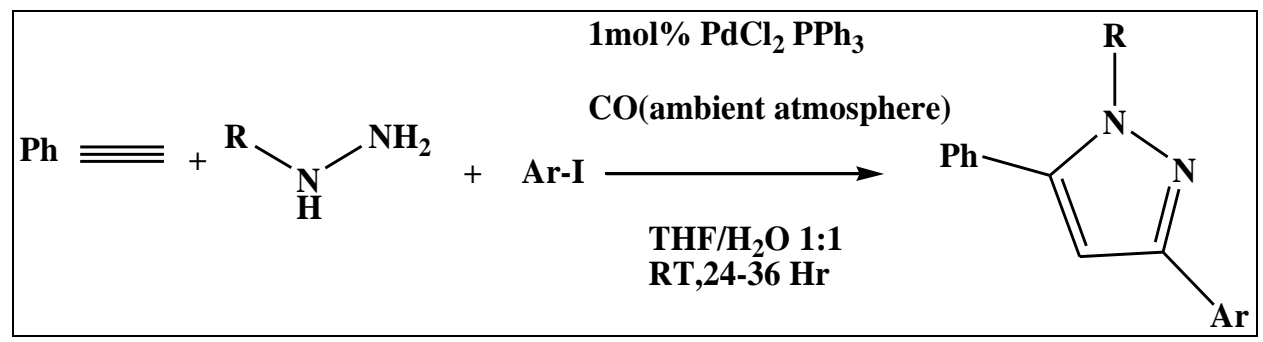

Method-4: In 1998, Powers et al. have synthesized pyrazoline derivatives by the reaction of chalcones and phenylhydrazine hydrochloride in the presence of sodium hydroxide in the absolute ethanol medium at $70{ }^{\circ} \mathrm{C}{ }^{18}$.

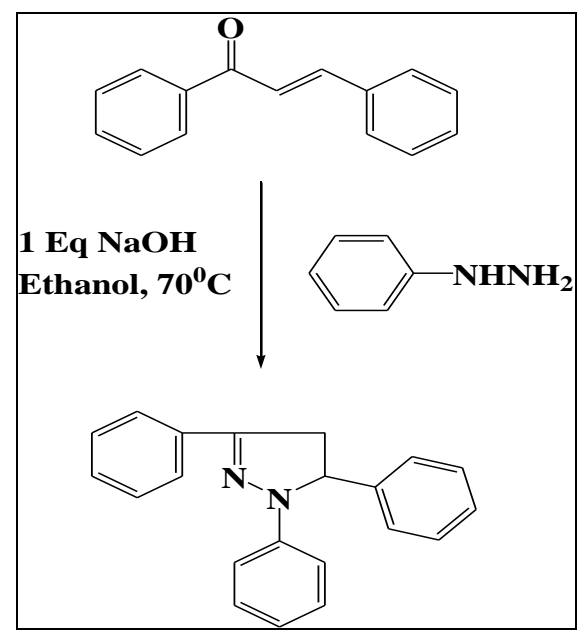

Method-5: Levai (2005), et al. have synthesized 3, 5-diaryl-2-pyrazolines by the reaction of chlorochalcones with hydrazine derivatives in acetic acid by refluxing for $3 \mathrm{~h}^{19}$.

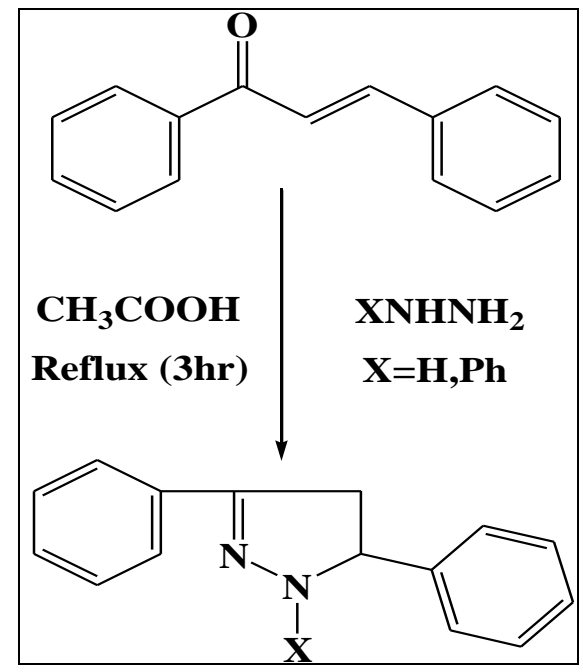

Synthesis of Some new 2-Pyrazoline Derivatives: A chalcone of 2-acetyl thiophene $(0.001 \mathrm{~mol})$ dissolved in $20 \mathrm{~mL}$ of ethanol and phenylhydrazine hydrochloride $(500 \mathrm{mg})$ was added to it. To this mixture, $0.3 \mathrm{~mL}$ of pyridine was added drop-wise at room temperature. After that, the mixture was refluxed for 5-6 h, and the solvent was evaporated completely. The reaction mixture was poured into ice-cold water. The solid mass that separated out was filtered, dried, and purified by column chromatography with ethyl acetate/ hexane and recrystallized from chloroform ${ }^{20}$.
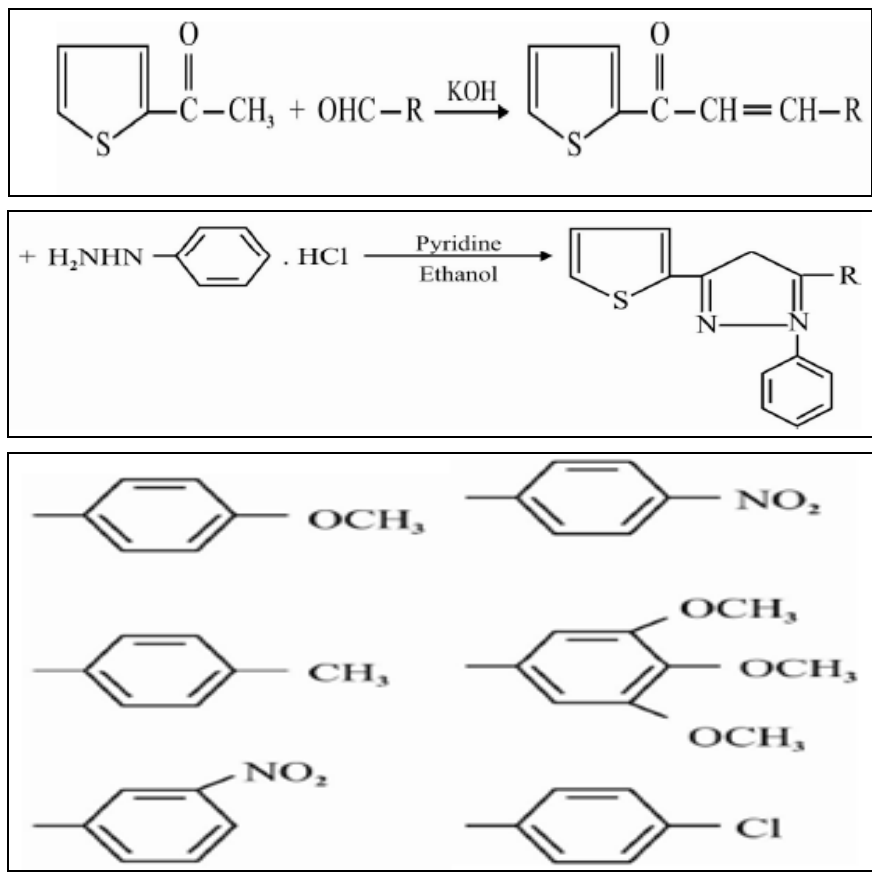

FIG. 4: SYNTHESIS OF SOME NEW 2-PYRAZOLINE DERIVATIVES

Synthesis of Pyrazoline from Recent Literature:

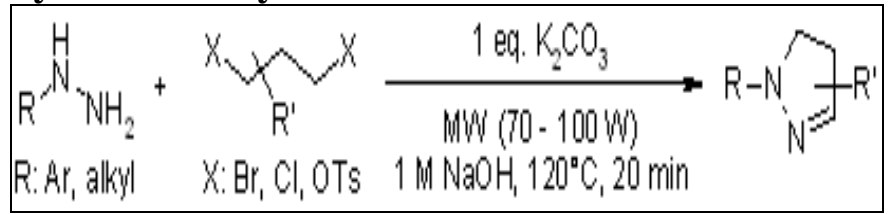

A one-pot synthesis of nitrogen-containing heterocycles from alkyl dihalides and primary amines and hydrazines occurs under microwave irradiation via a simple and efficient cyclo condensation in an alkaline aqueous medium ${ }^{21}$. 


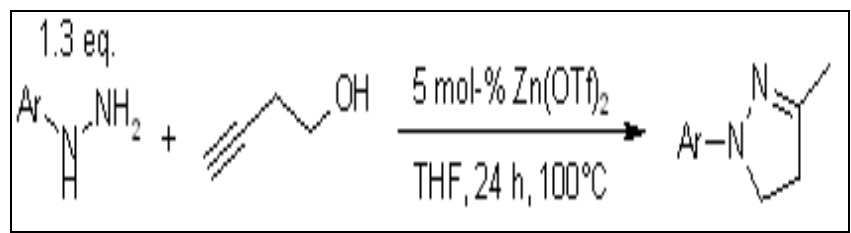

Arylhydrazines regioselectively react with 3butynol in the presence of a catalytic amount of zinc triflate to give aryl-substituted pyrazolines. The resulting products are easily oxidized in a onepot procedure to the corresponding pyrazoles ${ }^{22}$. Various 1 - acyl - 5 - hydroxyl - 4, 5 - dihydro - $1 \mathrm{H}$ pyrazoles have been prepared in good yields from the corresponding 2-alkyn-1-ones. The resulting dihydropyrazoles undergo dehydration and iodination in the presence of $\mathrm{ICl}$ and $\mathrm{Li}_{2} \mathrm{CO}_{3}$ at room temperature to provide 1-acyl-4-iodo- $1 \mathrm{H}$ pyrazoles $^{23}$.
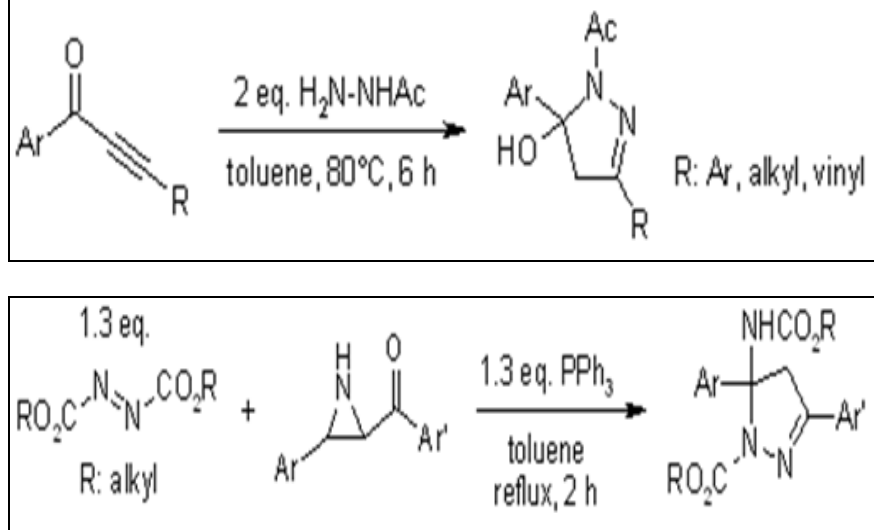

A novel, efficient, and general domino reaction of 2-acylaziridines with the Huisgen zwitterions furnishes 2-pyrazolines. A possible mechanism for the domino sequence is proposed ${ }^{24}$.

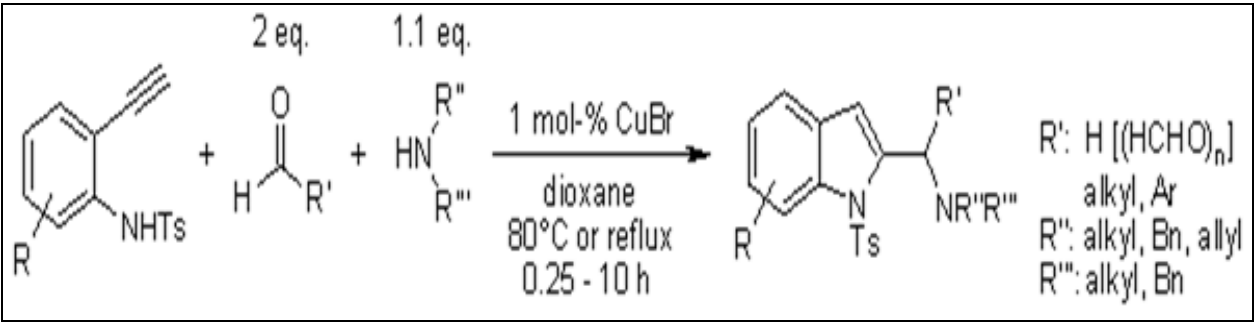

Construction of Nitrogen Heterocycles Bearing an Aminomethyl Group by Copper-Catalyzed Domino Three-Component Coupling-Cyclization ${ }^{25}$.

Pharmacological Review: Pyrazoline derivatives are known to possess broad-spectrum pharmacological activities like antidepressant, anticonvulsant, antimicrobial (such as antibacterial activity and antifungal activity), antihypertensive activity, antitubercular activity, muscle relaxant, tranquilising activity, psychoanaleptic activity, antiamoebic activity $26,27,28$.

Antidepressant Activity: E. Palaska et al. (1996) have synthesized some 1, 3, 5-triphenyl-2pyrazolines Fig. 5.

The methyl substitution at phenyl ring of position 3 of the pyrazoline ring enhanced the antidepressant activity. Replacement of the methyl group with chloro and bromo decreased the activity.

In addition, the introduction of a chloro substituent on the phenyl at position 5 decreases the antidepressant activity ${ }^{27}$.

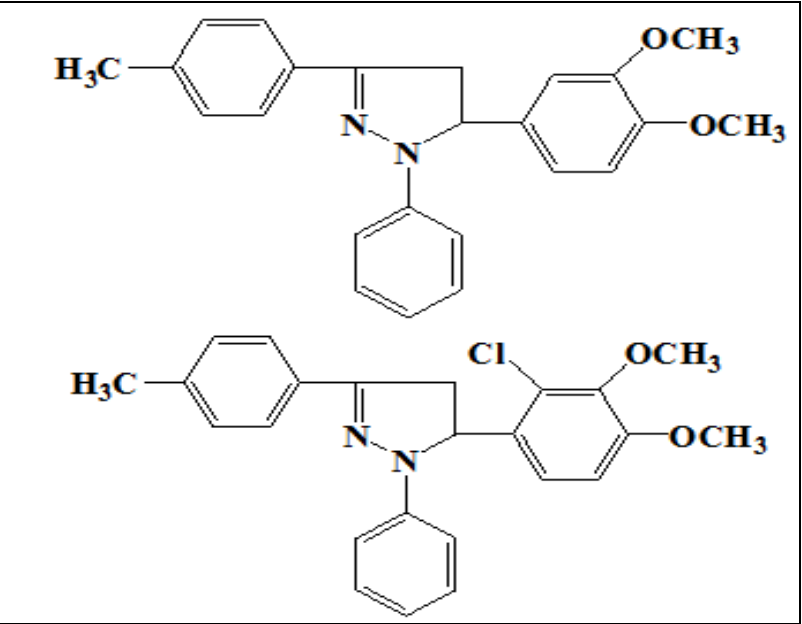

FIG. 5: SYNTHESIZE OF 1, 3, 5-TRIPHENYL-2PYRAZOLINES

Erhan Palaska et al. (2001) have synthesized some 3, 5-diphenyl-2-pyrazolines derivatives Fig. 6. The antidepressant activity showed that 4-methoxy and 4-chloro substituents at phenyl at 3 position of pyrazoline ring enhanced the antidepressant activity, and the replacement of these substituents with bromo and methyl groups decreased the activity ${ }^{26}$. 

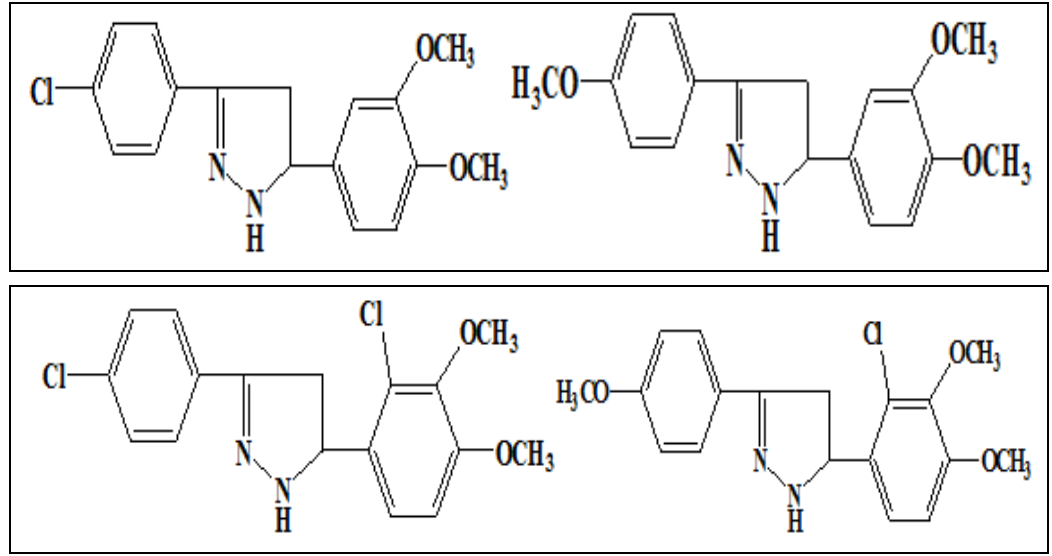

\section{FIG. 6: SYNTHESIZE SOME 3, 5-DIPHENYL-2-PYRAZOLINES DERIVATIVES}

Rajendra Prasad: et al., (2005) have synthesized some 1, 3, 5-triphenyl-2-pyrazolines and 3-(2hydroxynaphthalen - $1-\mathrm{yl})-1,5-$ diphenyl - 2 pyrazolines Fig. 7. The compounds possessing electron-releasing groups such as dimethylamino, methoxy and hydroxyl substituents, on both the aromatic rings at positions 3 and 5 of pyrazolines, considerably enhanced the antidepressant activity when compared to the pyrazolines having no substituents on the phenyl rings, and this is consistent with the observation made earlier by Parmar et $\mathrm{l}^{28}$.

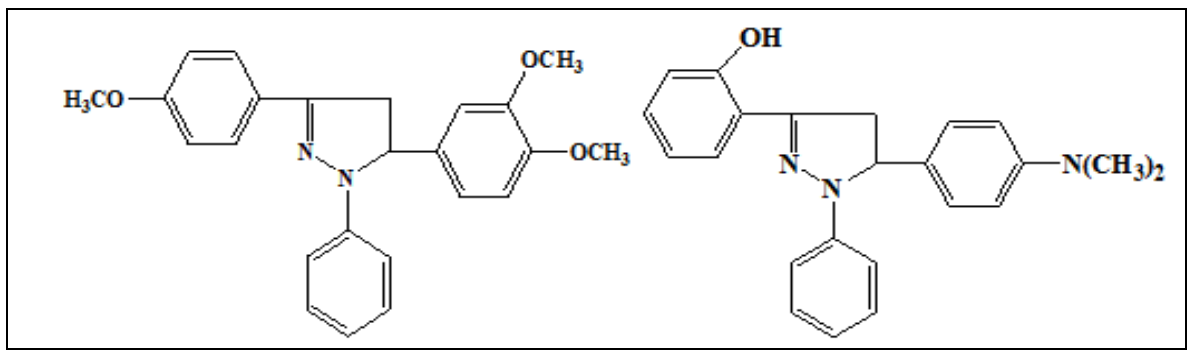

FIG. 7: SYNTHESIZE OF SOME PYRAZOLINE

ZuhalOzdemi: et al (2007) have synthesized 3-(2furyl)-pyrazoline derivatives and studied the antidepressant activities. A compound containing ethylthiocarbamoyl at 1 position of pyrazoline ring and compound containing allylthiocarbamoyl group at 1 position of pyrazoline group shows extensive antidepressant activity ${ }^{29}$.
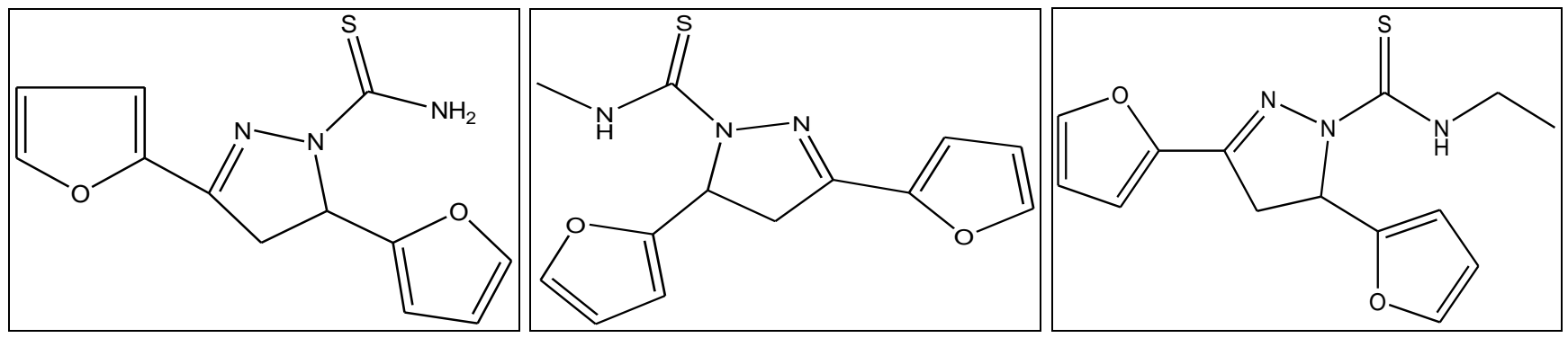

Mohamed Abdel Aziz et al, (2009) synthesized novel pyrazole derivatives and screened them for anticonvulsant and antidepressant activities.

The derivatives 8aand 8b Fig. 8 showed comparable antidepressant activity by using tail suspension behavioral despair test and anticonvulsant activity for derivatives $9 \mathrm{a}, 9 \mathrm{~b}$, and 9

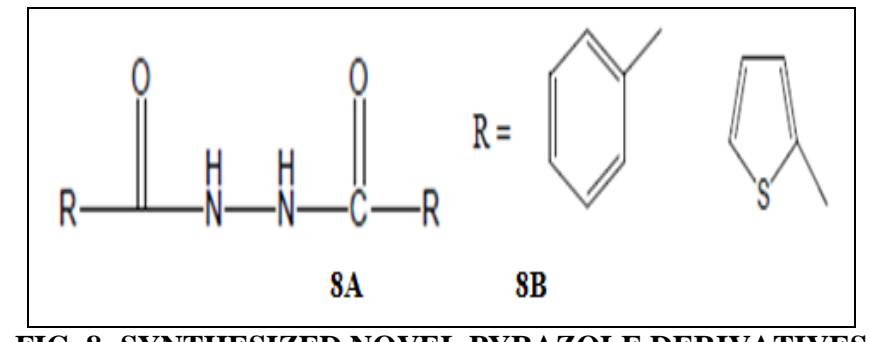
Fig. 9 by using PTZ induced seizures in mice ${ }^{30}$. 


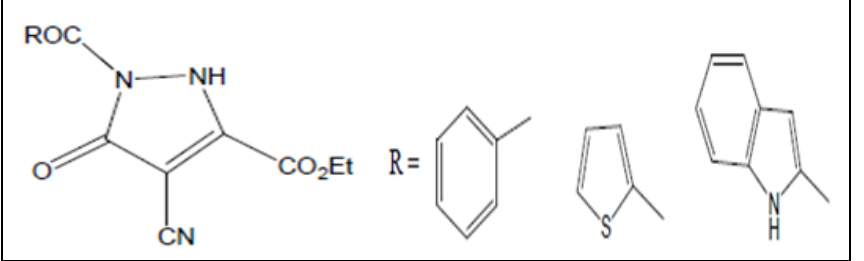

FIG. 9: SYNTHESIZED OF PYRAZOLE DERIVATIVE ABC

Anticonvulsant Activity: Zuhalet al., (2007) have synthesized some 3-(2-furyl)-pyrazoline derivatives. The anticonvulsant activities showed that compound containing pyrazoline group at position of pyrazoline and furyl group at position 3 show good anticonvulsant activity i.e., against MESinduced seizures. Compounds containing thiocarbamoyl group and its derivatives at position 1 of pyrazoline show activity against MES and scMet.induced seizures. Compounds having a 2-furyl substituent at the fifth position of the pyrazoline ring possess remarkable anticonvulsant activity ${ }^{28}$.

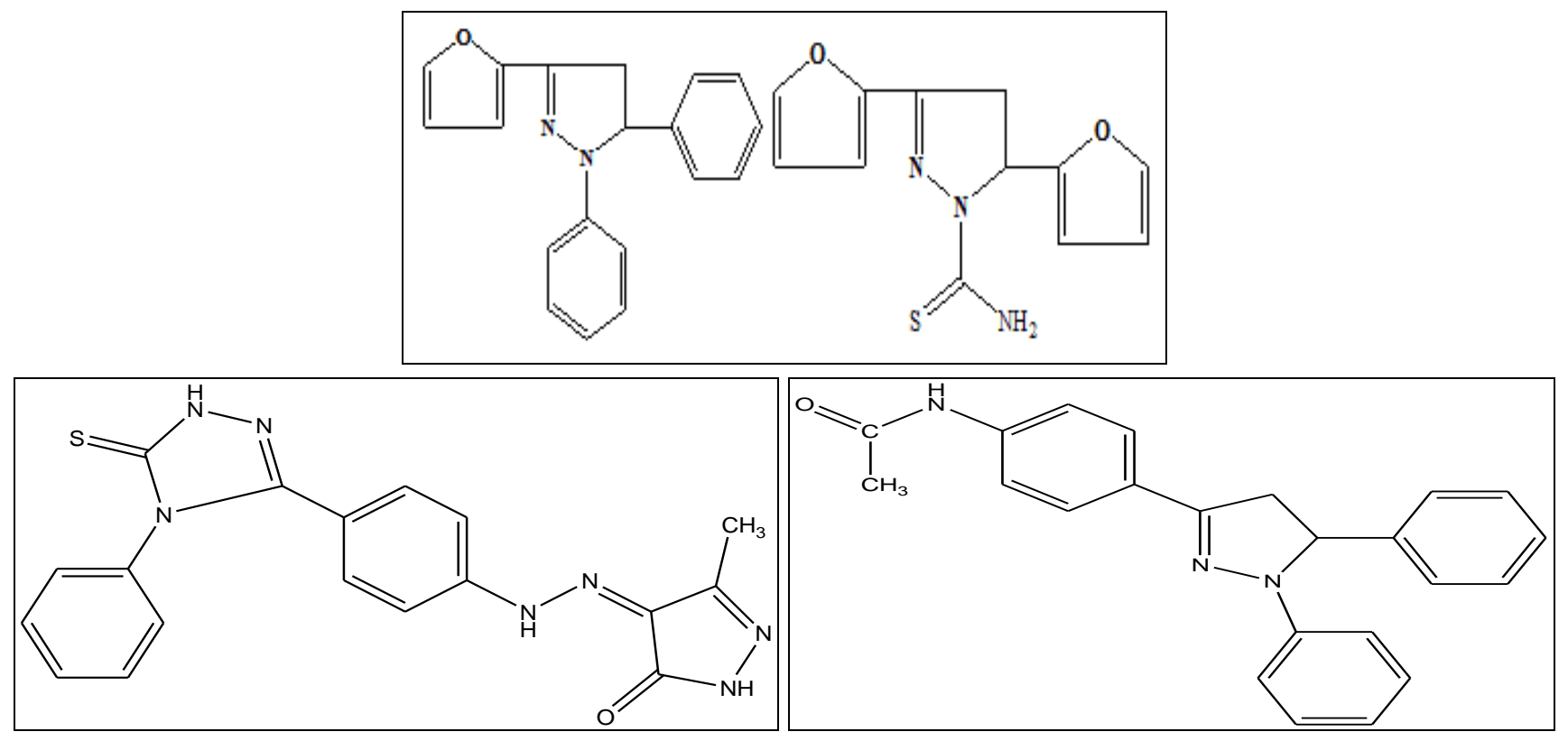

Kucukguzel et al. ${ }^{13}$ synthesized a new series of 4Arylhydrazono-2-pyrazoline-5-ones derivatives and evaluated for their anticonvulsant activity. Compound 6 showed $40 \%$ protection against pentylenetetrazole (PTZ) - induced seizures in albino Swiss mice ${ }^{31}$. Singh et al.. synthesized several 3-(3-Acetoamino) phenyl-1, 5-substituted phenyl-2-pyrazolines [12] and evaluated for their anticonvulsant activity ${ }^{32}$.

Antimycobacterial Activity: Mamolo et al., synthesized 5-Aryl-1-isonicotinoyl-3- (pyridin-2yl)-4, 5-dihydro-1H-pyrazole derivatives 13 and tested for their in-vitro antimycobacterial activity. The compounds showed an interesting activity against a strain of $M$. Tuberculosis ${ }^{33}$. Ozdemiret al synthesized new 1-[(N, N-disubstituted thiocarbamoylthio) acetyl]-3-(2-thienyl)-5-aryl-2pyrazoline derivatives 14 and evaluated for in-vitro antimycobacterial activity against $M$. Tuberculosis ${ }^{34}$. Zampieriet al synthesized several 1-(3, 5-Diaryl4, 5-dihydro- $1 H$-pyrazol-4yl)- $1 H$-imidazole derivatives 15 and tested for their in vitro antifungal and antimycobacterial activities. These imidazole derivatives showed an excellent antifungal activity against a clinical strain of $C$. albicans and an interesting antitubercular activity against $M$. Tuberculosis ${ }^{35}$. Kiniet al., synthesized a novel series of heterocyclic $\mathrm{o} / \mathrm{m} / \mathrm{p}$ substituted diphenyl ether derivatives 16 and determined their activity against the strain of Mycobacterium ${ }^{36}$.

Ali et al., synthesized a series of 5-(-4-(Substituted) phenyl) - 3 - (4 - hydroxyl - 3 - methylphenyl) -4, 5 - dihydro - $1 H$-1- pyrazolyl - 2 - toluidino methanethione and 5-(Substituted) phenyl-3-(4hydroxy - 3 - methylphenyl) - 4, 5-dihydro- $1 \mathrm{H}$-1pyrazolyl-2-methoxyanilino methanethione17and tested for their in-vitro antitubercular activity against $M$. tuberculosis. Among the synthesized compounds, compound Anilino-3-(4-hydroxy-3methylphenyl) - 5 - (2, 6 - dichlorophenyl) - 4, 5dihydro- $1 H$-1-pyrazolylmethanethione was found to be a more active agent against $M$. Tuberculosis 37. 

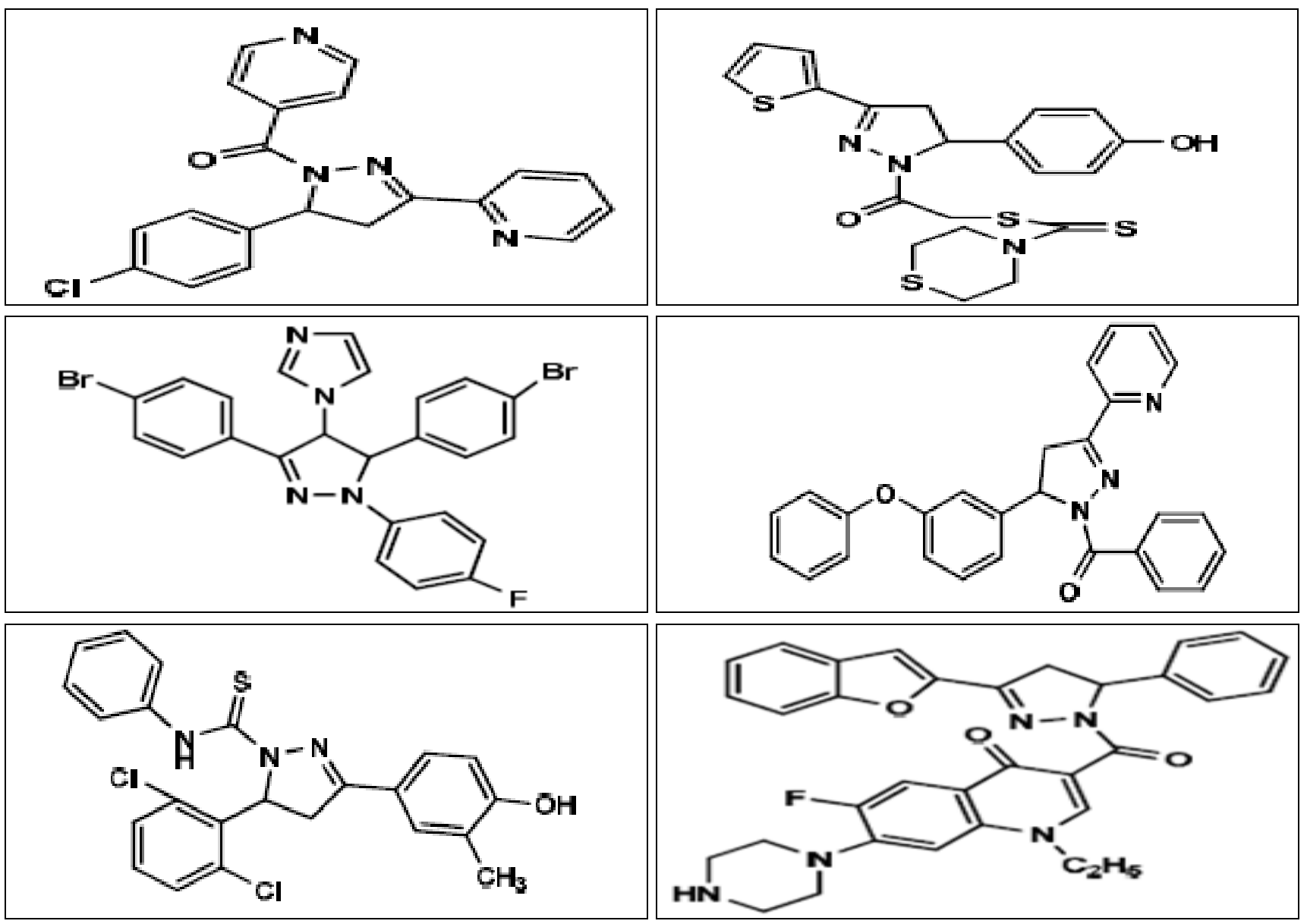

Babu et al. synthesized and evaluated biological activity of 1, 3, 5-Trisubstituted pyrazolines bearing benzofuran ${ }^{18}$. They were found to be antitubercular, antimicrobial and antiinflammatory in nature ${ }^{38}$.

M Ali et al., (2007) have synthesized some novel pyrazoline derivatives and have evaluated the antitubercular activity. Compounds with hydroxy phenyl substituted showed more active when compared to the standard drug $\mathrm{INH}^{39}$.

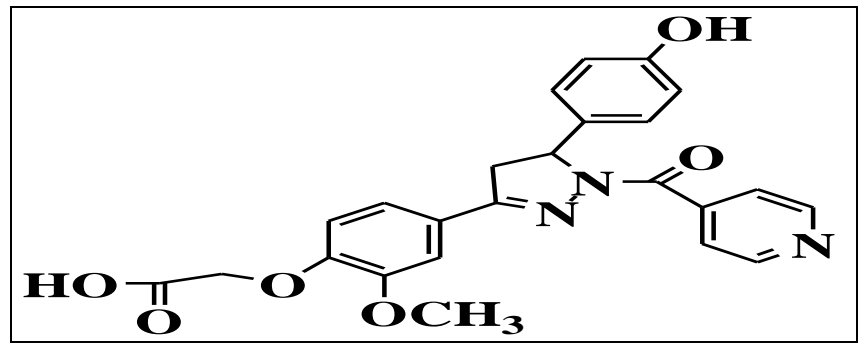

Antimicrobial Activity: Samir Bondock et al., 2010, had synthesized a series of substituted pyrazole derivatives. The given compound 20 was found to exhibit the most potent in-vitro antifungal \& F. Oxysporum comparable with Chloroamphenicol ${ }^{40}$. Smaail Radi et al., (2010) synthesized novel pyrazole derivatives and these derivatives were evaluated for their antimicrobial activity determined by agar plate diffusion technique. Antibacterial activity: Against antibacterial strains Escherichia coli and determined by agar plate diffusion method. Antifungal activity: Against two fungal strains Saccharomyces cerevisae and Fusarium oxysporum f. sp.ablicans. Streptomycin was used as reference compound in performing antimicrobial assay. These derivatives Fig. 8 were found to be most potent $^{41}$.

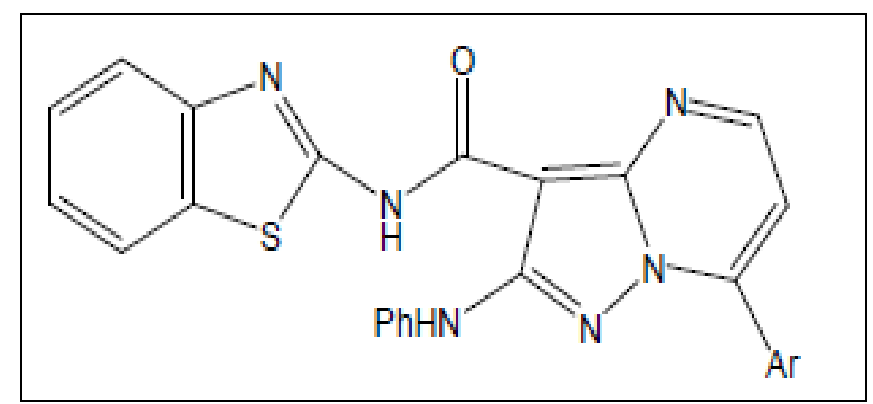




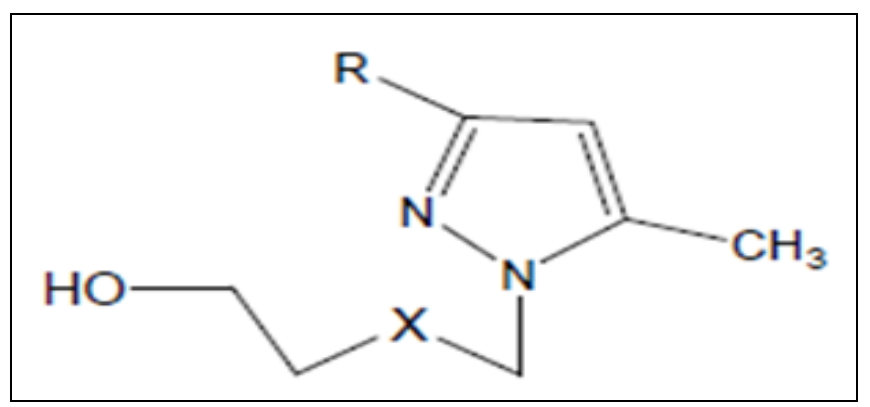

S. K. Sahu et al., (2008) synthesized novel pyrazoline derivatives. The derivatives $\mathrm{a}, \mathrm{b} \& \mathrm{c}$ Fig. 25 showed potent Antimicrobial activity: Antibacterial activity; by muller hinton agar (Himedia) plates by agar diffusion cup-plate method for Staphylococcus aureus, Salmonella typhi \& E. coli. Antifungal activity; was tested on sabouraud dextrose agar plates by cup-plate method against Candida albicans \& Aspergillus niger).

In both of these assays ciprofloxacin and cotrimazole was used as standard drugs. Also the compounds 2 c \& 2 e Fig. 9 showed effective analgesic (by Tail flick method) and antiinflammatory (by Carageenan induced rat paw edema method) ${ }^{42}$.

\begin{tabular}{ccc}
\hline Compounds & $\mathbf{R}$ & $\mathbf{X}$ \\
\hline 21 & $\mathrm{CH}_{3}$ & $\mathrm{O}$ \\
22 & $\mathrm{CH}_{3}$ & $\mathrm{CH}_{2}$ \\
23 & $\mathrm{CO}_{2} \mathrm{Et}$ & $\mathrm{O}$ \\
24 & $\mathrm{CO}_{2} \mathrm{Et}$ & $\mathrm{CH}_{2}$ \\
\hline
\end{tabular}

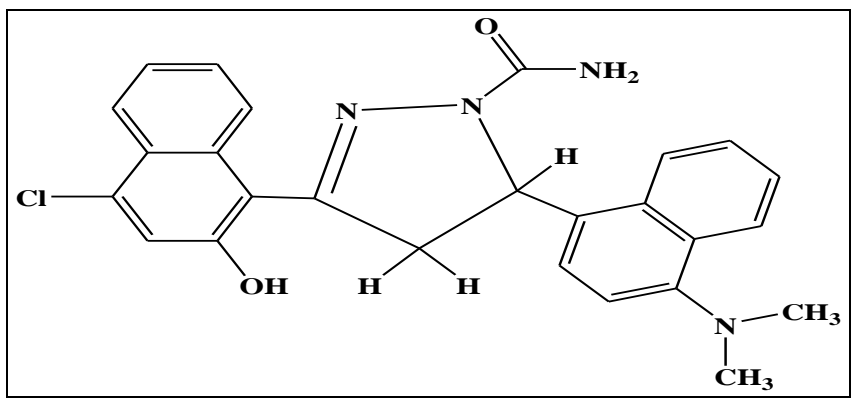

FIG. 26: 3, 5-DINAPHTHYL SUBSTITUTED 2PYRAZOLINES

Abdelwahab et al synthesized 1-(Benzofuran-2-yl)4- nitro-3-arylbutan-1-ones and 3-(Benzofuran-2yl)-4, 5- dihydro - 5-aryl - 1-[4-(aryl)-1, 3-thiazol2-yl]-1H-pyrazoles 7 and evaluated their antibacterial and antifungal activities ${ }^{45}$. Stirrett et al., 29 synthesized small molecules 29 with structural similarities to siderophores and evaluated them as novel antimicrobials against Mycobacterium tuberculosis and Yersinia pestis ${ }^{46}$.

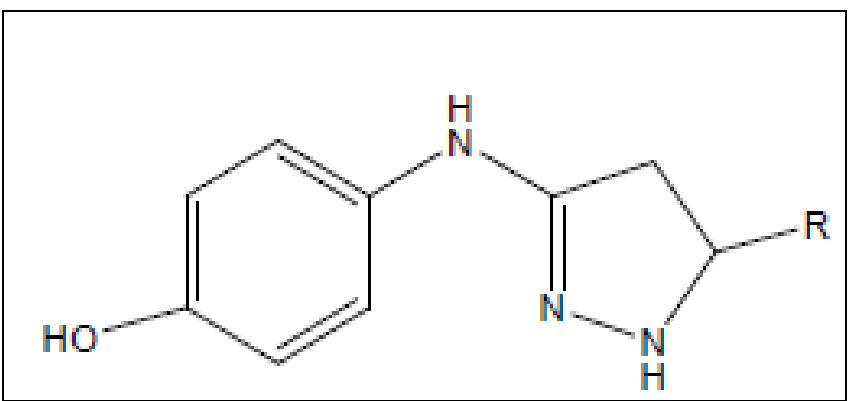

FIG. 25: SYNTHESIZED PYRAZOLINE DERIVATIVES

\begin{tabular}{cc}
\hline Compounds & \multicolumn{1}{c}{$\mathbf{R}$} \\
\hline $\mathrm{A}$ & $-4-\mathrm{NO}_{2}-\mathrm{C}_{6} \mathrm{H}_{4}$ \\
$\mathrm{~B}$ & $-2-\mathrm{OH}-\mathrm{C}_{6} \mathrm{H}_{4}$ \\
$\mathrm{C}$ & $-4-\mathrm{Cl}-\mathrm{C}_{6} \mathrm{H}_{4}$ \\
\hline
\end{tabular}

Davood Azarifar et al., (2002) have synthesized and characterized some new 3, 5-dinaphthyl substituted 2-Pyrazolines and studied their antimicrobial activity. All the compounds showed activity against the test organisms Klebsiella pneumonia and Staphylococcus aureus. Among these, one was found to be the most active since this compound could inhibit the microbial growth at lower concentrations ${ }^{43}$. Ozdemir et al synthesized several 1-(4-Aryl-2-thiazolyl)- 3 - (2 thienyl) -5 - aryl -2 -pyrazoline derivatives 27 and investigated their antimicrobial activities against Escherichiacoli, Staphylococcus aureus, Salmonella typhimurium, Bacillus cereus, Streptococcus faecalis, Aeromona shydrophila, Candida albicans and Candida glabrata ${ }^{44}$.

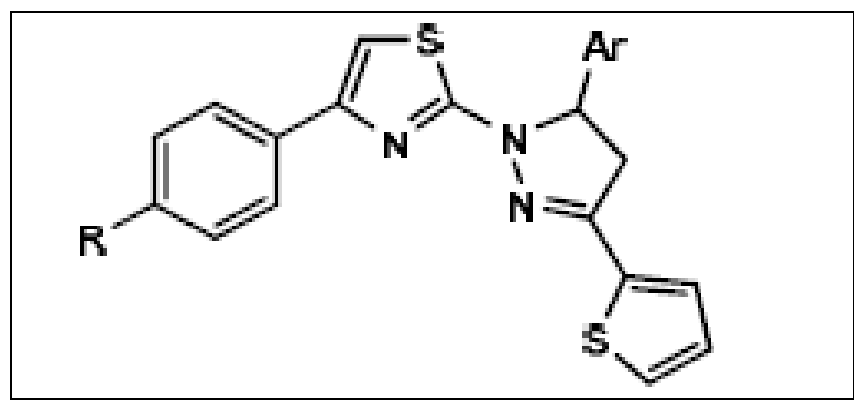

FIG. 27: 1-(4-ARYL-2-THIAZOLYL) - 3-(2-THIENYL)5-ARYL-2-PYRAZOLINE DERIVATIVES

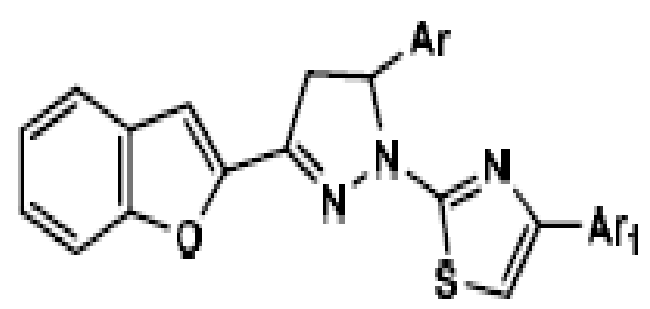

FIG. 28: 1-(BENZOFURAN-2-YL)-4- NITRO-3-ARYLBUTAN1-ONES AND 3-(BENZOFURAN-2-YL)-4, 5- DIHYDRO-5ARYL-1-[4-(ARYL)-1, 3-THIAZOL-2-YL]-1H-PYRAZOLES 7 


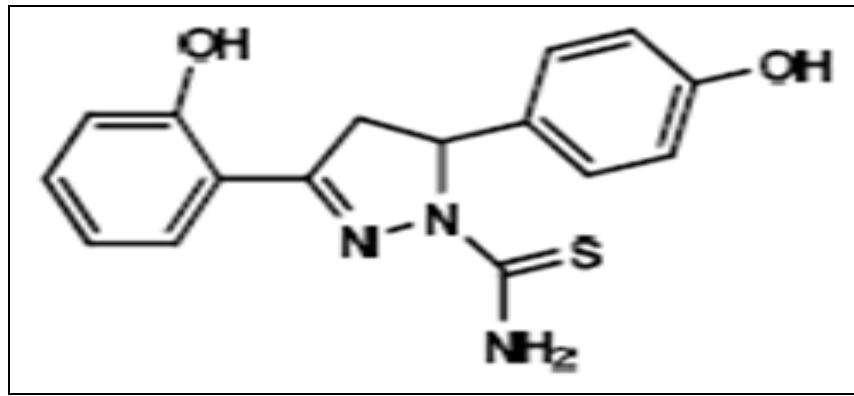

FIG. 29: SMALL MOLECULES OF PYRAZOLINE

Abunada et al. synthesized several 1, 3-Diaryl-5(cyano-,aminocarbonyl- and ethoxycarbonyl) -2pyrazoline, pyrrolo [3, 4-c]pyrazole-4, 6-dione and 1, 3, 4, 5-tetraaryl-2-pyrazoline derivatives 30 and screened their antimicrobial activities against $E$. coli, S. aureus, Asperagillus flavus and C. albicans 47.

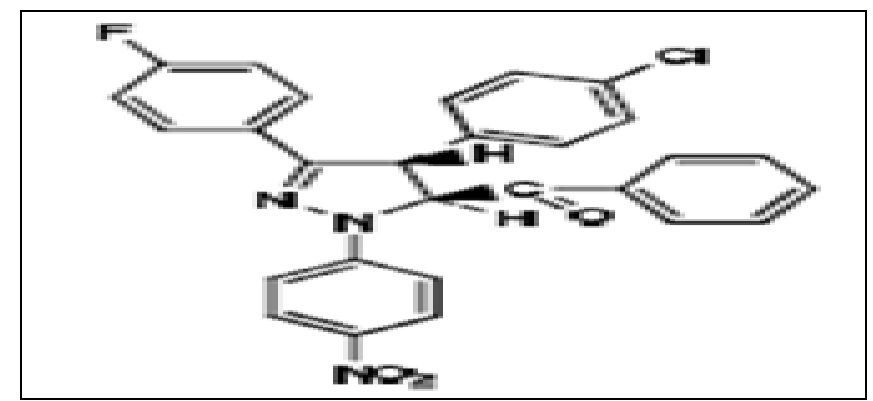

FIG. 30: PYRAZOLINE DERIVATIVES 30

Bhatt et al., synthesized different types of pyrazolines and cyan pyridines 31 as potential antimicrobial agents. They found that these have remarkable activity against $B$. mega, B. subtilis, $E$. coli, and M. tuberculosis ${ }^{48}$.

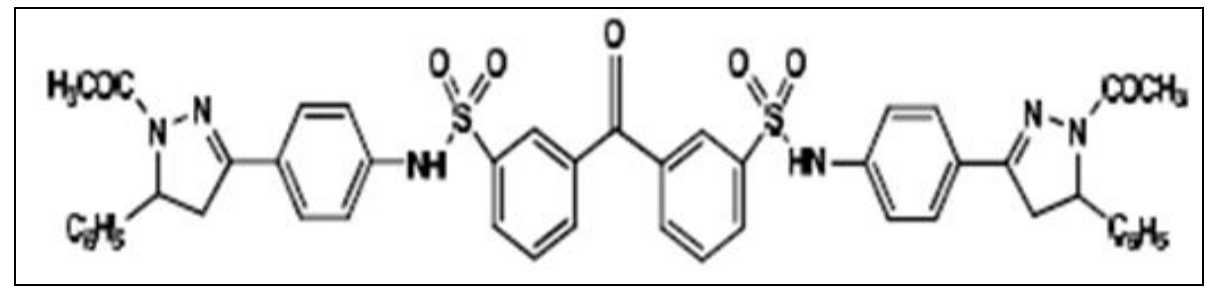

FIG. 31: SYNTHESIZED DIFFERENT TYPES OF PYRAZOLINES

Bharmal et al., synthesized some pyrazoline derivatives as biologically active agents. All the compounds 32 showed antimicrobial activity against $S$. typhosaand A. niger ${ }^{48}$.

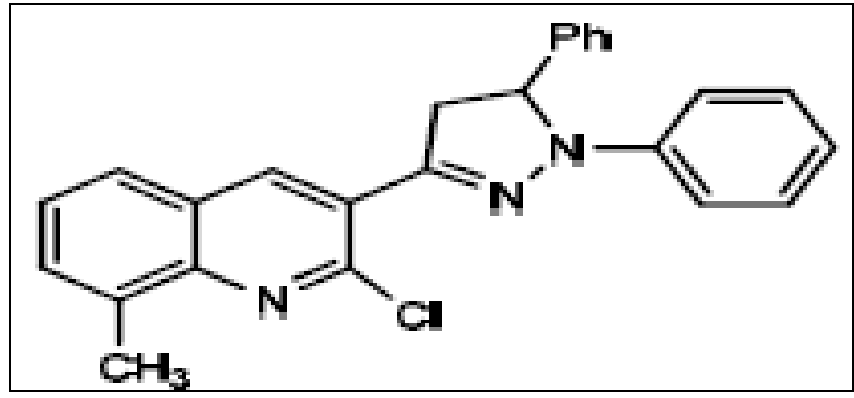

FIG. 32: SYNTHESIZED SOME PYRAZOLINE DERIVATIVES

Antiamoebic Activity: Kakul Husainet.al., have synthesized some Novel Pd (II) complexes of 1-Nsubstituted 3-phenyl-2-pyrazoline derivatives.
They have shown that among all the cyclized ligands, the $\mathrm{N}$-cyclo-octyl amine in this series showed a close value for antiamoebic activity with the reference drug metronidazole ${ }^{49}$.

Abid et al., synthesized a series of new $1-\mathrm{N}$ substituted cyclized pyrazoline analogues of thiosemicarbazones by cyclisation of Mannich bases with thiosemicarbazide were subsequently evaluated for their antiamoebic activity by microdilution method against the strain of Entamoeba histolytica.

A series of palladium (II) complexes of $1-N-$ substituted thiocarbamoyl - 3,5 - diphenyl - 2 pyrazoline derivatives were reported possessed better antiamoebic activity as compared to other ligands and complexes ${ }^{50}$.

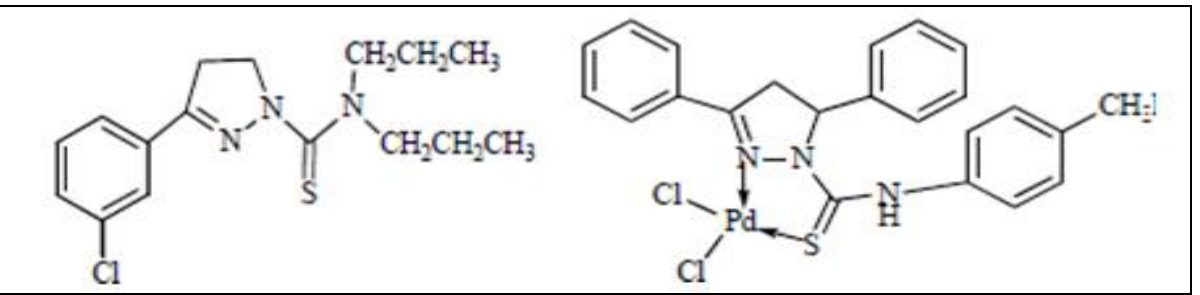

FIG. 33: SERIES OF NEW 1-N-SUBSTITUTED CYCLISED PYRAZOLINE 
Bhat and co-workers reported bis-pyrazolines 34 prepared by cyclization of chalcones with $\mathrm{N}-4$ substituted thiosemicarbazides under basic conditions. The antiamoebic activity results showed that the compound with aromatic substituents at the thiocarbamoyl group was more active than those with the cyclic groups 51 .

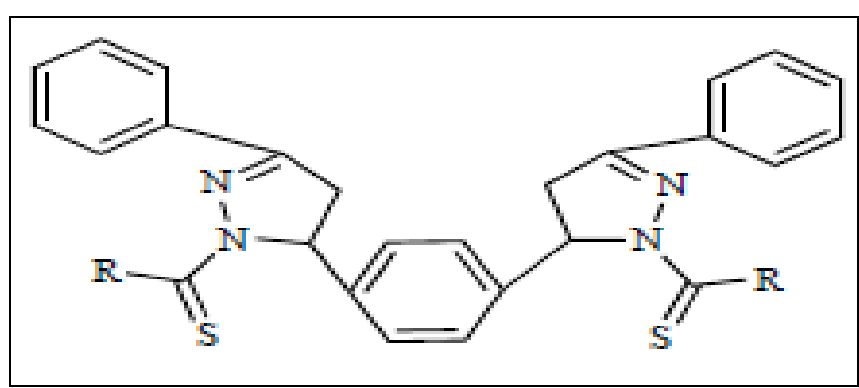

FIG. 34: BIS-PYRAZOLINES

Antiviral Activity: Osama I et al (2009) synthesized 4, 5-disubstituted pyrazole derivatives. The derivative containing $\mathrm{R}=\mathrm{Cl}$ group Fig. 16 showed the potent antiviral activity against a broad panel of viruses in different cell cultures (HEL Cell cultures).

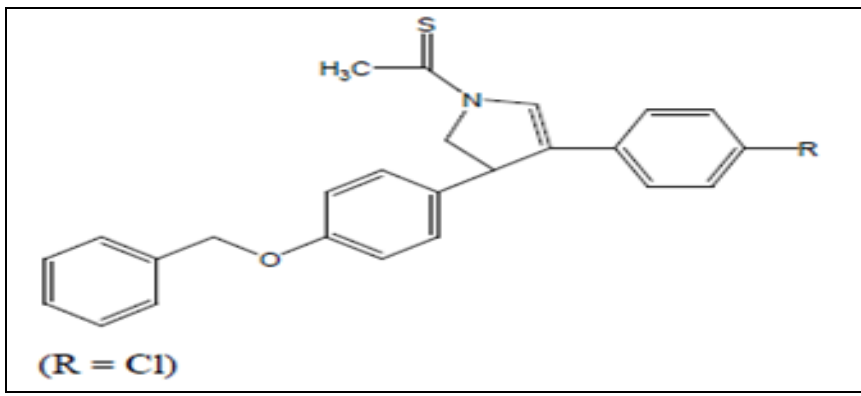

FIG. 35: 4, 5-DISUBSTITUTED PYRAZOLE DERIVATIVES

Analgesic, Antipyretic Activity: Flora F. Barsoum et al., (2009) synthesized bis (3- aryl-4, 5-dihydro1H Pyrazole-1-thio carboxamide derivatives. The derivative 36 with substitution, $\mathrm{A}=4-\mathrm{O}\left(\mathrm{CH}_{2}\right) 2 \mathrm{O}$ 4', $\mathrm{R}=\mathrm{Ph}$, showed potent antiinflammatory activity against carrageen an-induced rat paw edema test ${ }^{52}$.

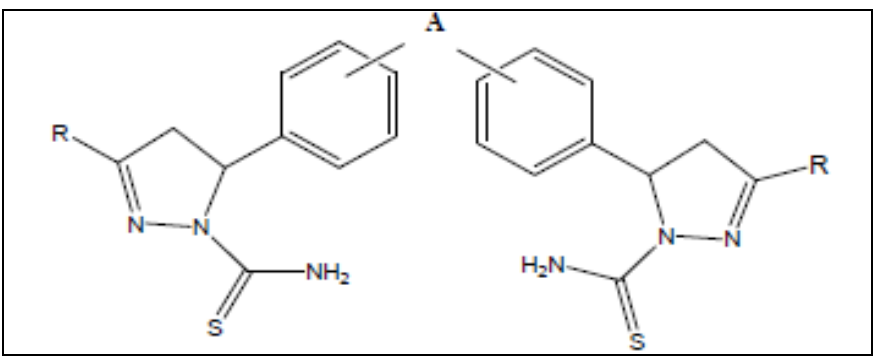

$\left(\mathrm{A}=4-\mathrm{O}\left(\mathrm{CH}_{2}\right) 2 \mathrm{O}-4^{\prime}, \mathrm{R}=\mathrm{Ph}\right)$

FIG. 36: BIS (3- ARYL-4, 5-DIHYDRO-1H PYRAZOLE1-THIO CARBOXAMIDE DERIVATIVES
Ekta Bansal et al., (2001) have synthesized 1acetyl-5-substituted aryl - 3 - (b-aminonaphthyl) 2 -pyrazolines derivatives. They show that Compound substituted with phenyl ring having methoxy group at eitherortho or para positions exhibited the maximum percent inhibition of oedema ${ }^{53}$.

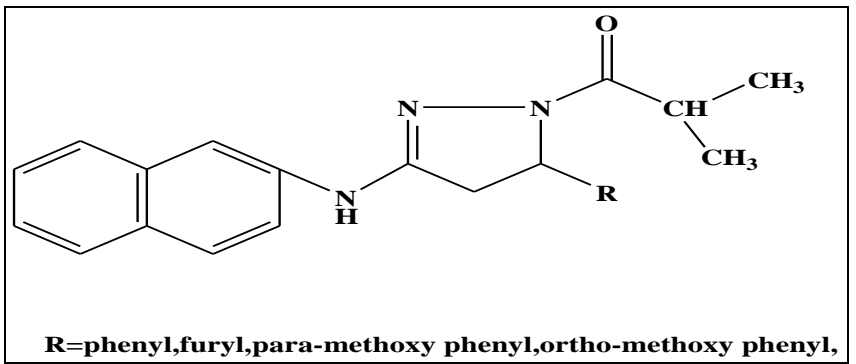

FIG. 37: 1-ACETYL-5-SUBSTITUTED ARYL-3-(BAMINONAPHTHYL)-2-PYRAZOLINES

Rathish et al. synthesized new 1, 3, 5-trisubstituted pyrazolines bearing benzene sulphonamides 38 and evaluated their anti-inflammatory activity, several compounds demonstrated promising activity. Various 1-(4- sulfamylphenyl)-3-trifluoromethyl-5indolyl pyrazolines 39 were prepared and screened for cyclooxygenase-2 (COX-2) and lipoxygenase (LOX) inhibition ${ }^{54}$.

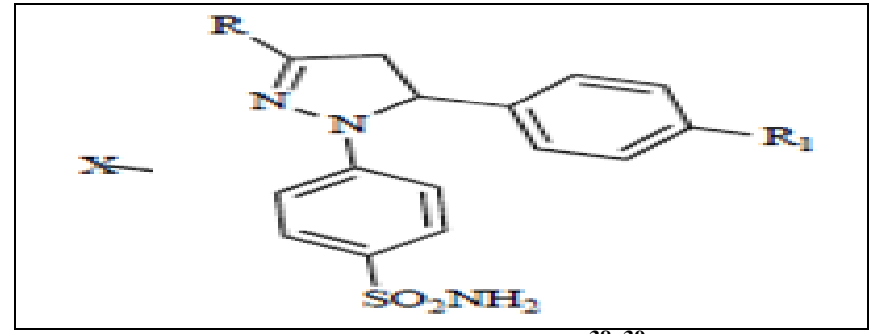

FIG. 38: COMPOUND ${ }^{38,39}$

Amir et al., synthesized a series of 3-(4-Biphenyl)5 -substituted phenyl-2-pyrazolines and 1-Benzoyl3-(4-biphenyl)-5-substituted phenyl-2- pyrazolines and screened for their anti-inflammatory and analgesic activity. Among the compounds studied, compound 40 showed more potent antiinflammatory and analgesic activity than the standard drug, along with minimum ulcerogenic index 55 .

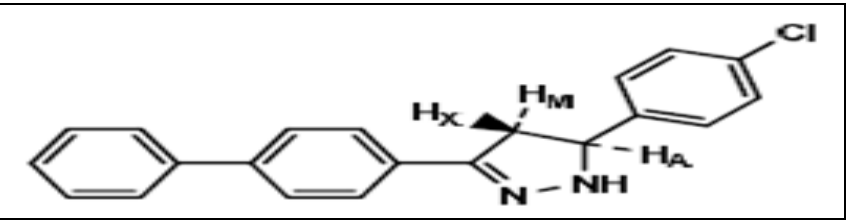

FIG. 40: 3-(4-BIPHENYL)-5-SUBSTITUTED PHENYL2-PYRAZOLINES AND 1-BENZOYL-3-(4-BIPHENYL)5-SUBSTITUTED PHENYL-2- PYRAZOLINES 
Barsoum et al synthesized a variety of Bis (3-aryl4, 5-dihydro-1H-pyrazole-1-carboxamides) and screened for their anti-inflammatory properties and PGE2 inhibitory properties (at a dose level of 50 mg.kg-1) utilizing the in-vivo acute carrageenaninduced paw oedema standard method in rats. They exhibited that many of the tested compounds reveal considerable anti-inflammatory properties, especially [41.a and 41.b], which reveal remarkable activities relative to indomethacin (which was used as a reference standard at a dose of $10 \mathrm{mg} . \mathrm{kg}-1$ of body weight). They exhibited lower ulcer index values than the used reference standard (indomethacin) ${ }^{56}$.
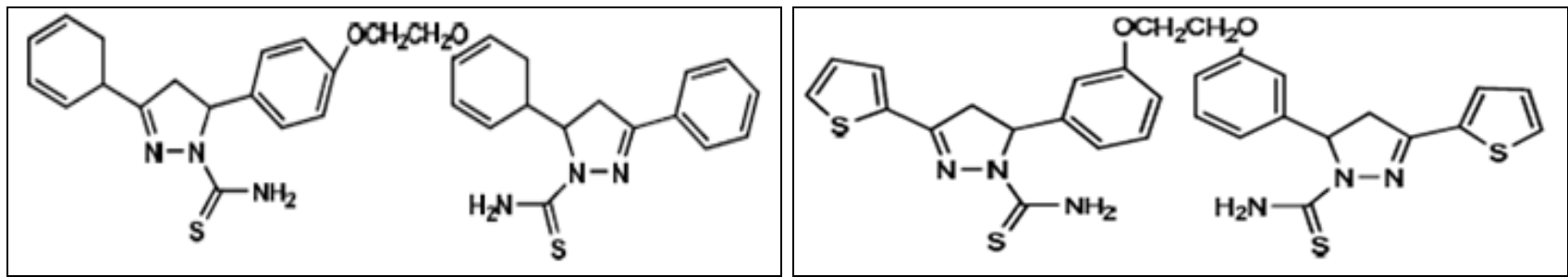

FIG. 41A: COMPOUND 41A, 41B: COMPOUND 41B

Rani et $a l^{22}$ synthesized pyrazoline derivatives and evaluated them for their anti-inflammatory activity against carrageenan induced oedema in albino rats at a dose of 50 mg.kg-1 oral. All the compounds of this series showed promising anti-inflammatory activity. The most active compound of the series, 3 [1-Acetyl-5-( $p$-hydroxyphenyl)-2- pyrazolin-3-yl] indole ${ }^{32}$ was found to be most potent, which had shown higher percent of inhibition of oedema, lower ulcerogenic liability, and acute toxicity than the standard drug phenylbutazone ${ }^{57}$.

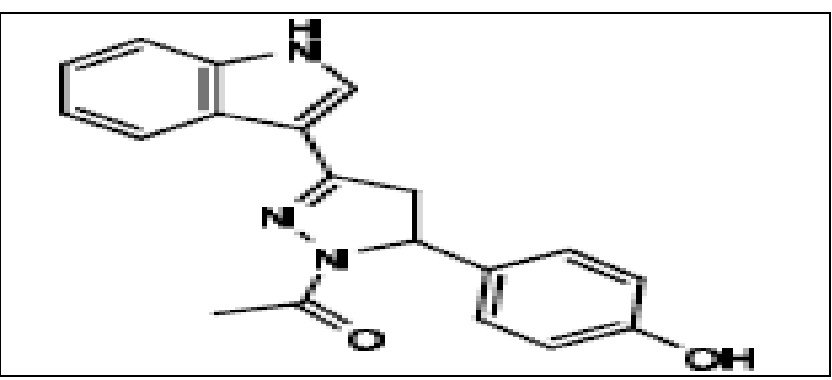

FIG. 42: 3-[1-ACETYL-5-(P-HYDROXYPHENYL)-2PYRAZOLIN-3-YL] INDOLE

Kelekc et al., synthesized a novel series of 1Thiocarbamoyl - 3 - substituted phenyl-5-(2pyrrolyl)-4, 5-dihydro-( $1 H$ )-pyrazole derivatives and tested for their in vivo anti-inflammatory activity by two different bio-assays namely, carrageenan-induced oedema and acetic acidinduced increase in capillary permeability in mice. In addition, analgesic and ulcerogenic activities were also determined. The combined antiinflammatory data from in-vivo animal models showed that compound 43 exhibited antiinflammatory activity comparable to that of indomethacin with no ulcerogenic effects ${ }^{58}$.

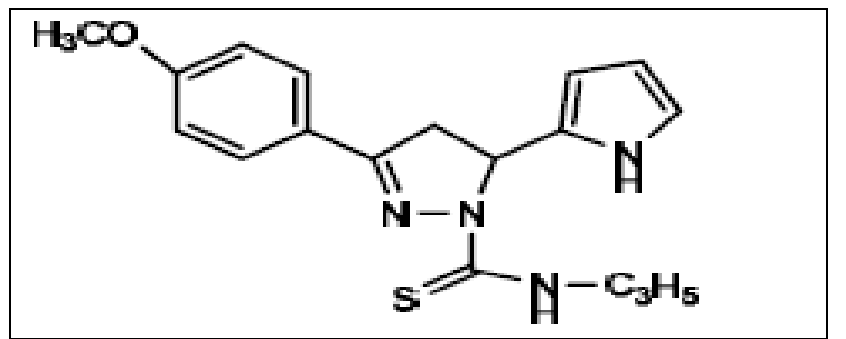

FIG. 43: 1-THIOCARBAMOYL-3-SUBSTITUTED PHENYL5-(2-PYRROLYL)-4, 5-DIHYDRO-(1H)-PYRAZOLE

Khode et al., ${ }^{24}$ synthesized a novel series of 5(Substituted) aryl - 3 - (3 - coumarinyl) - 1 phenyl-2-pyrazolines and screened for in-vivo antiinflammatory and analgesic activities at a dose of 200 mg.kg-1 of body weight. Among the 12 prepared compounds, Compound 44 exhibited significant anti-inflammatory activity in model of acute inflammation such as carrageenan-induced rat edema paw ${ }^{59}$.

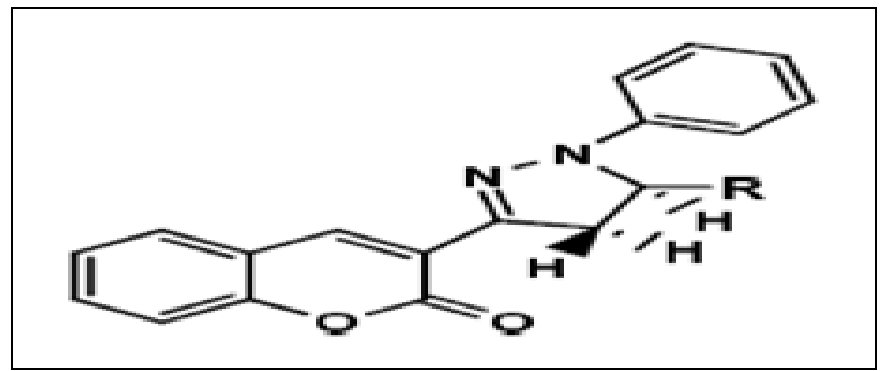

FIG. 44: 5-(SUBSTITUTED) ARYL-3-(3-COUMARINYL)1-PHENYL-2-PYRAZOLINES

Shoman et al., synthesized a group of NO-donating 2-pyrazoline derivatives 45 and evaluated for their anti-inflammatory activity using carrageenaninduced rat paw edema and compared it to a wellknown NSAID, indomethacin, as a reference drug. 
The ability of the prepared compounds to induce gastric toxicity was also evaluated ${ }^{60}$. Kaplancikli et al., synthesized 1-[(Benzo-xazole / Benzimidazole-

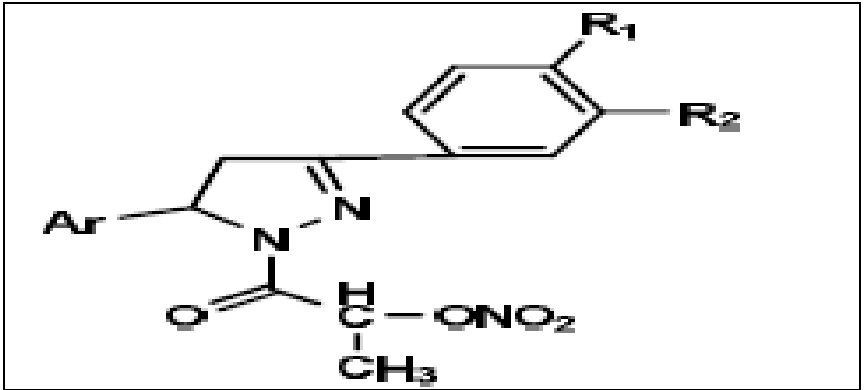

FIG. 45: NO-DONATING 2-PYRAZOLINE DERIVATIVES

Anticancer Activity: Peng-cheng LVet al., (2010) synthesized a series of pyrazole derivatives. The compound 47 having $\mathrm{R} 1=3$, $4-2 \mathrm{CH} 3$ and $\mathrm{R} 2=4$ $\mathrm{OCH} 3$ substitution own high antiproliferative activity ${ }^{62}$. Havrylyuk et al., ${ }^{5}$ synthesized several novel thiazolone-based compounds containing 5Aryl-3-phenyl-4, 5-dihydro-1Hpyrazol- $\quad$ 1-yl

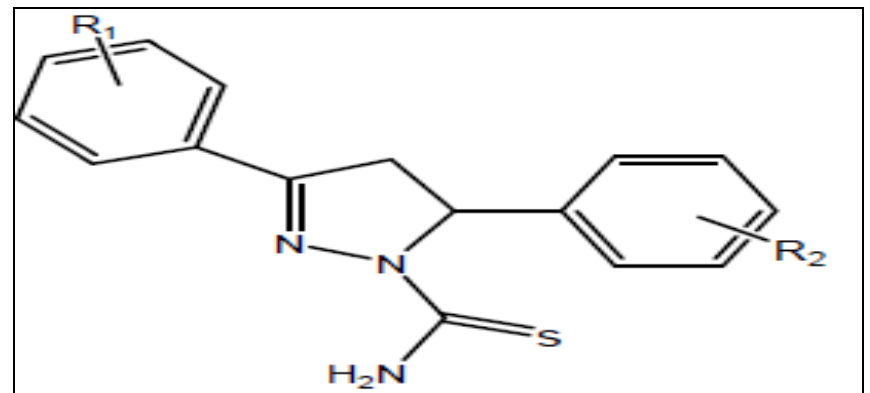

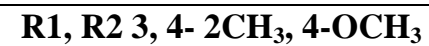

FIG. 47: SERIES OF PYRAZOLE DERIVATIVES

Bhat et al., synthesized a series of substituted pyrazoles 49 and evaluated for in-vitro cytotoxic activity against a panel of human cancer cell lines. Out of 93 compounds screened, 8 compounds showed marked activity ${ }^{64}$. Manna et al., synthesized a series of substituted pyrazolines (1Acetyl - 3, 5 - diphenyl - 4, 5 - dihydro - $(1 H)$ - 2-yl) thioacetyl] pyrazoline derivatives 46 and evaluated for antinociceptive activities ${ }^{61}$.

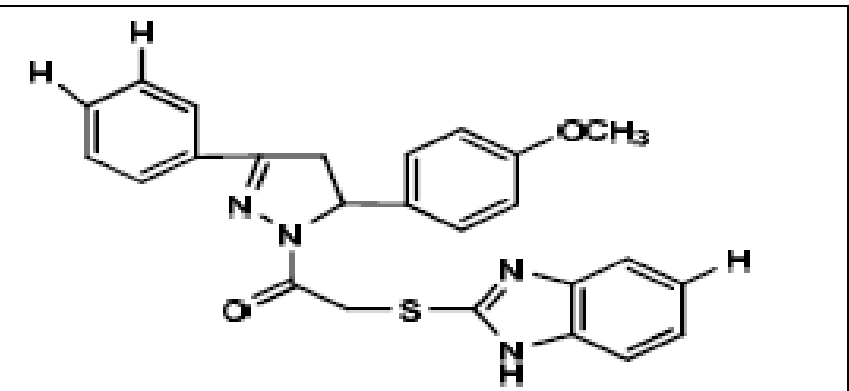

FIG. 46: 1-[(BENZOXAZOLE/BENZIMIDAZOLE-2-YL) THIOACETYL] PYRAZOLINE

framework and tested for in-vitro anticancer activity. Most of them displayed anticancer activity on leukemia, melanoma, lung, colon, CNS, ovarian, renal and prostate, and breast cancer cell lines. The most efficient anticancer compound 48 was found to be active with selective influence on colon cancer cell lines ${ }^{63}$.

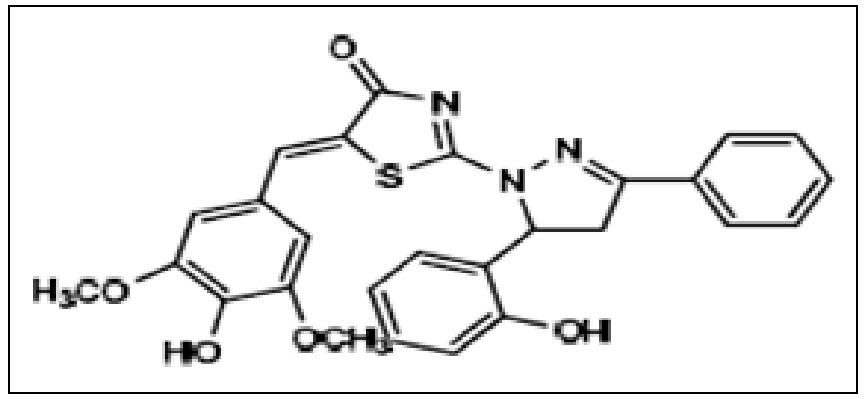

FIG. 48: 5-ARYL-3-PHENYL-4, 5-DIHYDRO-1HPYRAZOL- 1-YL

pyrazole) and evaluated for their anticancer activity and for their ability to inhibit $P$-glycoproteinmediated multidrug resistance by direct binding to a purified protein domain containing an ATPbinding site and a modulator interacting region. Compounds 50a and 50b have been found to bind to $P$-glycoprotein with greater affinity ${ }^{65}$.

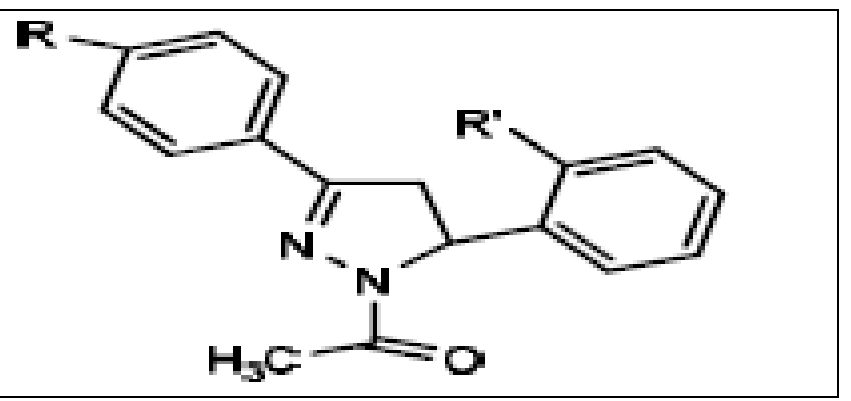

FIG. 50: 1-ACETYL-3,5-DIPHENYL-4, 5-DIHYDRO-(1H)- S PYRAZOLE) 
Hypotensive Activity: Turan-Zitouni et al., synthesized some 1-(4-Arylthiazol-2-yl)-3, 5diaryl-2-pyrazoline derivatives 51 and investigated their hypotensive activity by the tail-cuff method using clonidine as reference standard ${ }^{66}$.

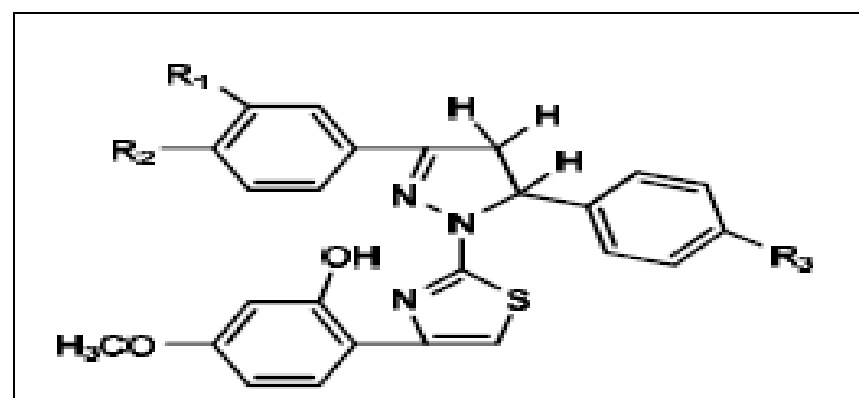

FIG. 51: 1-(4-ARYLTHIAZOL-2-YL)-3，5-DIARYL-2PYRAZOLINE

ACE-Inhibitory Activity: Macro Bonesi et al., (2010) synthesized a series of pyrazole derivatives Fig. 5 and investigated their potential activity as Angiotensin-I-converting enzymes inhibitory activity by performing assay. This derivative of pyrazole Fig. 52 showed effective ACE-inhibitory activity ${ }^{67}$.

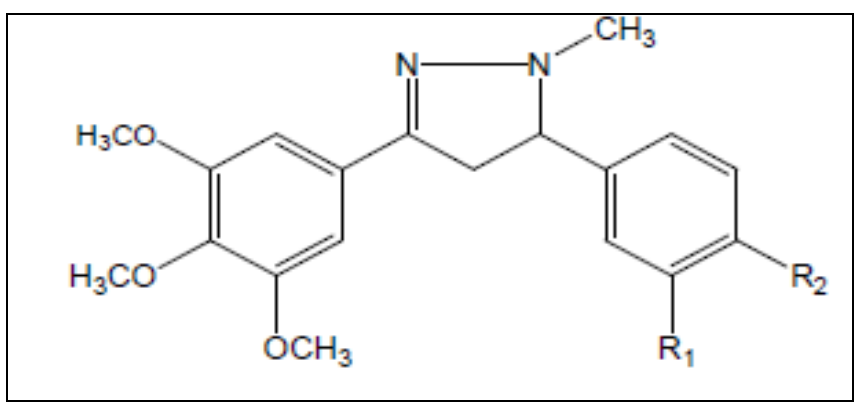

$\mathrm{R1} \mathrm{R2} \mathrm{NO}_{2} \mathrm{OCH}_{3}$

FIG. 52: DERIVATIVE OF PYRAZOLE

Cholesterol Inhibitory Activity: Jeong et al ${ }^{61}$ synthesized a series of 3-(3, 5-Di-tert-butyl-4hydroxyphenyl) - 5 - (multi - substituted 4hydroxyphenyl)-2-pyrazolines 53 and evaluated their inhibitory action on acyl-CoA: cholesterol acyltransferase ${ }^{68}$.

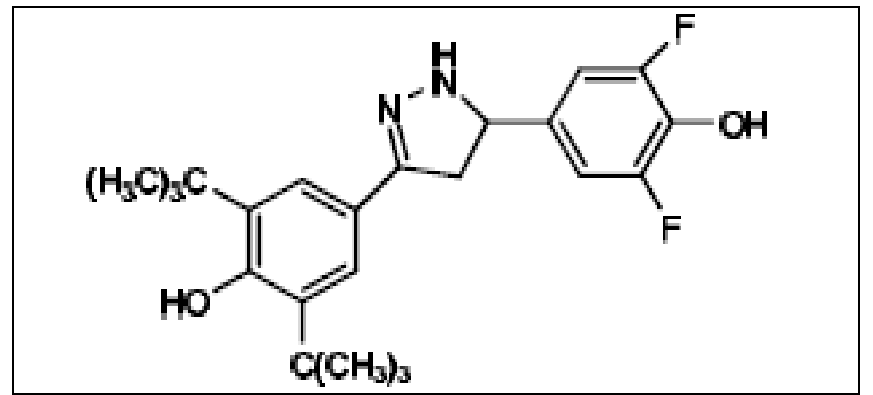

FIG. 53: 3-(3, 5-DI-TERT-BUTYL-4- HYDROXYPHENYL) - 5 - (MULTI-SUBSTITUTED 4-HYDROXYPHENYL)-2-PYRAZOLINES
Cannabinoid CB1 Receptor Antagonists: Cannabinoid CB1 receptor antagonists are currently the subject of intensive research due to their highly promising therapeutic prospects. NCEs having CB1 antagonistic properties have recently been disclosed by several pharmaceutical companies and some academic research groups; Srivastava et al. prepared a number of analogues of diaryl dihydropyrazole-3-carboxamides 54 and evaluated them for appetite suppression and bodyweight reduction in animal models ${ }^{69}$.

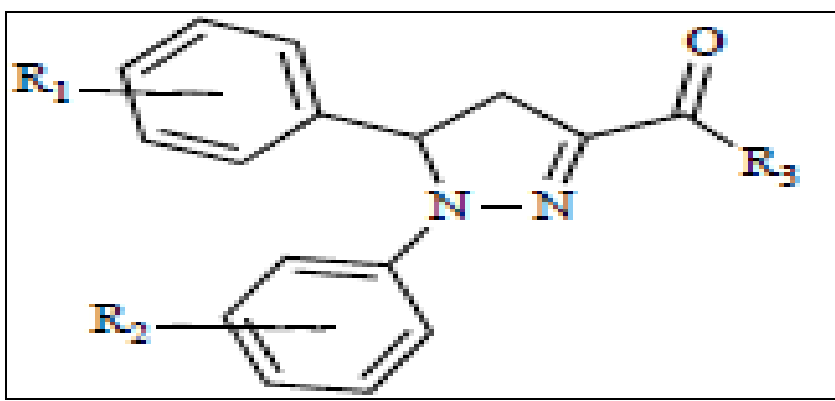

FIG. 54: DIARYL DIHYDROPYRAZOLE-3-CARBOXAMIDES

Nitric Oxide Synthase Inhibitor: Nitric oxide synthase (NOS) is an enzyme in the body that contributes to synaptic transmission from one neuron to another, to the immune system and to dilating blood vessels. It does so by synthesis of nitric oxide (NO) from the terminal nitrogen atom of L-arginine in the presence of NADPH. There are three known isoforms of NOS; two are constitutive (cNOS) i.e., neural (nNOS) \& endothelial (eNOS), and the third is inducible (iNOS), which is associated with biological functions brain and other parts of the body. Camacho et al. designed and synthesized 19 new nNOS inhibitors with a 4,5dihydro- $1 H$-pyrazole structure 55 in an attempt to find new compounds with neuroprotective activity.

Compounds 1-cyclopropanecarbonyl-3-(2-amino-5 - chlorophenyl) - 4, 5 - dihydro- $1 H$-pyrazole and 1cyclopropanecarbonyl $-3-(2-$ amino $-5-$ methoxyphenyl)- 4,5-dihydro- $1 \mathrm{H}$-pyrazole show the highest activities with inhibition percentages of $70 \%$ and $62 \%$, respectively. Similarly, Carriónet al. reported preparation and the preliminary evaluation of a series of 1-alkyl-3-benzoyl-4,5-dihydro$1 H$ pyrazoles 56 and 1-alkyl-3-benzoyl- $1 H$ pyrazoles 57 as potential inhibitors of both neuronal and inducible nitric oxide synthases (nNOS and iNOS $)^{70}$. 


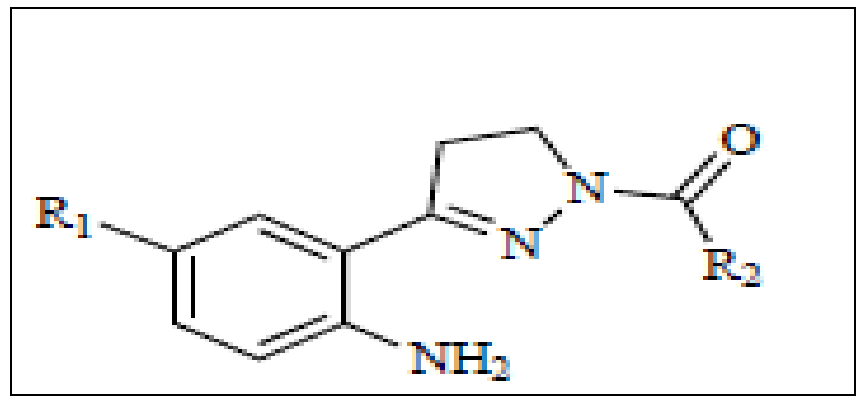

FIG. 55: COMPOUND 55

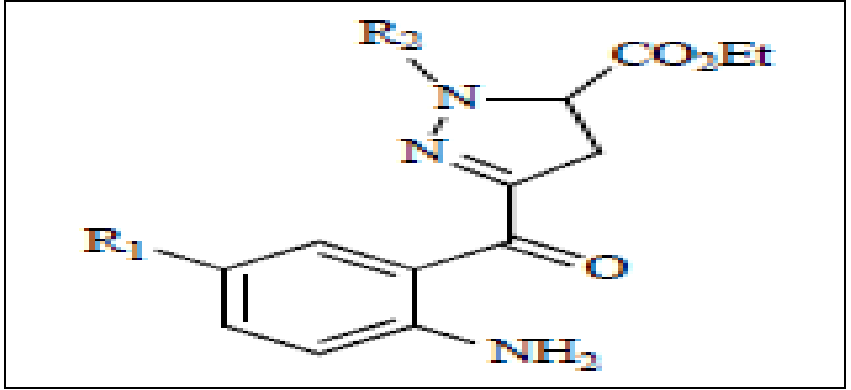

FIG. 56: COMPOUND 56

Steroidal Activity: Zhang et al., designed and synthesized a novel series of pyrazolines 58 and evaluated by in-vivo screening as tissue-selective androgen receptor modulators (SARMs).

Structure-activity relationships (SAR) were investigated at the R1 to R6 positions as well as the core pyrazoline ring and the anilide linker. Overall, strong electron-withdrawing groups at the R1 and $\mathrm{R} 2$ positions and a small group at the R5 and R6 positionare optimal for AR agonist activity. Mifepristone is a non-selective antagonist of 3-

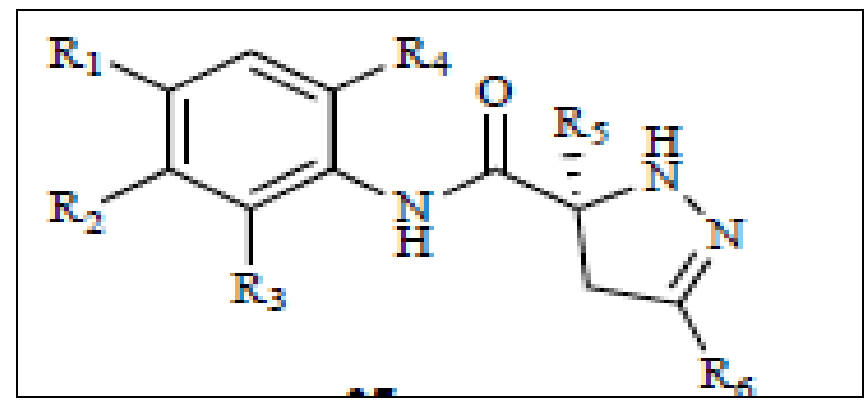

FIG. 58: SYNTHESIZED A NOVEL SERIES OF PYRAZOLINES

Antioxidant Activity: Babu et al., ${ }^{63}$ synthesized a series of pyrazoline derivatives and evaluated for antioxidant activity against standard drug ascorbic acid. Compound 60 showed excellentantioxidant activity as compared with ascorbic acid ${ }^{72}$.

Polarity Probes Activity: Svechkarev et al., 53 synthesized two novel 1, 3, 5-Triphenyl-2-pyra-

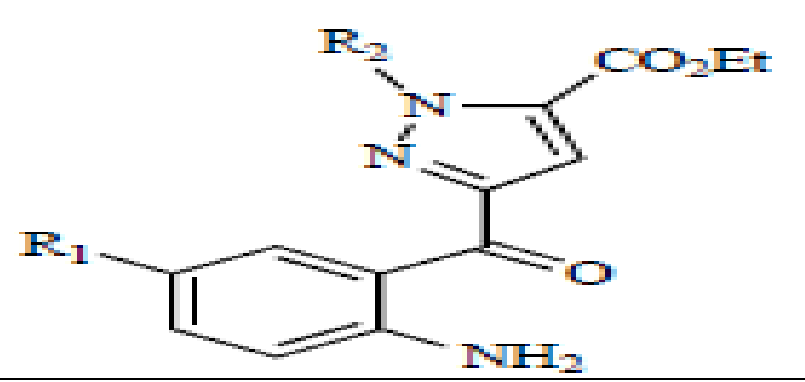

FIG. 57: COMPOUND 57

oxosteroid receptors with both abortifacient and anti-endometriotic activities. Non-steroidal mimetics of mifepristone and progesterone are important templates for modulation of the progesterone receptor $(\mathrm{PR})$.

Jones et al., identified 4-substituted pyrazolines derivatives 59 by docking of compounds into a PR homology model, and when the same was synthesized and tested, exhibited functional antagonism of $\mathrm{PR}{ }^{71}$.

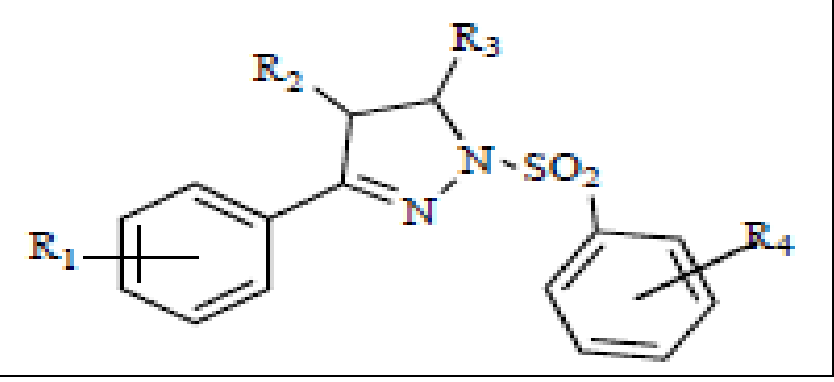

FIG. 59: 4-SUBSTITUTED PYRAZOLINES DERIVATIVES

zoline moiety containing derivatives of 3hydroxychromone [61a, 61b] and discussed the prospects of the practical application of these compounds exhibiting high solvatofluorochromism into analytical chemistry and biophysics as effective ratiometric polarity probes proceeding from the data on their fluorescent properties ${ }^{73}$. 


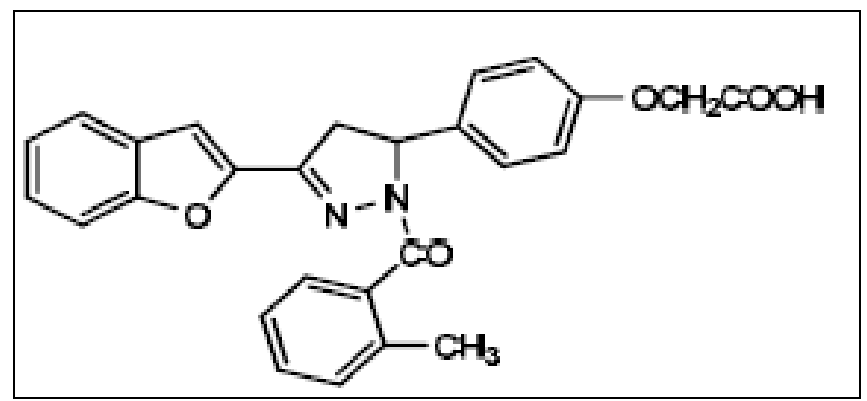

FIG. 60: SYNTHESIZED A SERIES OF PYRAZOLINE

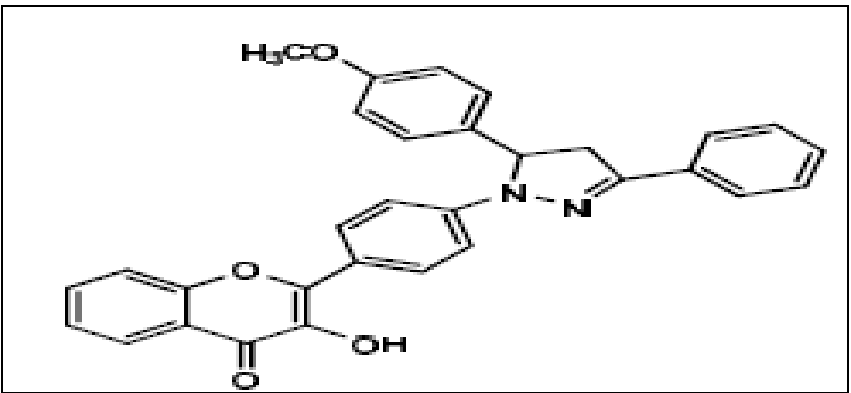

FIG. 61A: COMPOUND 61A

Amine Oxidase Inhibitory Activity: Manna et al. 62 synthesized a novel series of 1-Acetyl-3, 5diphenyl-4,5-dihydro- $(1 H)$-pyrazole derivatives and investigated for the ability to inhibit selectively MAOs, swine kidney oxidase, and bovine serum amine oxidase. 1-Acetyl-3-(2,4-dihydroxyphenyl)5-(3-methylphenyl)-4,5- dihydro-( $1 H$-pyrazole 62 showed to be a potent monoamine oxidase inhibitor.

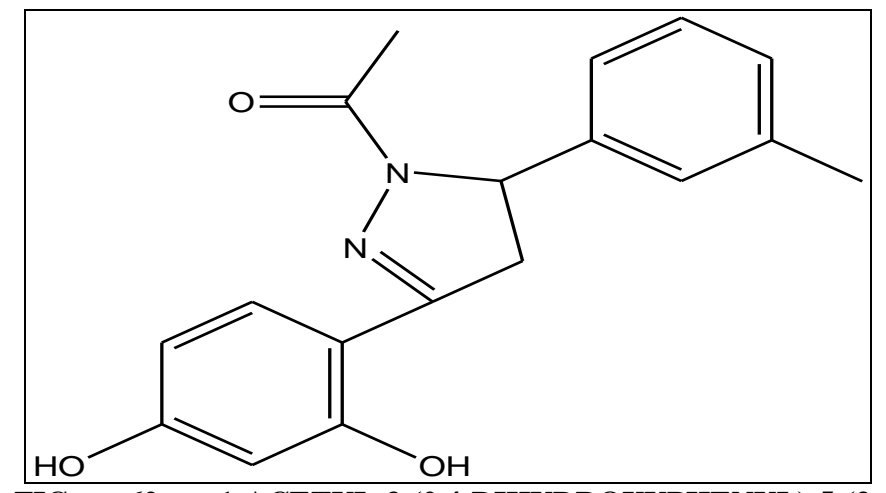

FIG. 62: 1-ACETYL-3-(2,4-DIHYDROXYPHENYL)-5-(3METHYLPHENYL)-4,5- DIHYDRO-(1H)-PYRAZOLE

MAO-inhibitory Activity: Chimenti et al. ${ }^{57}$ synthesized a series of N1-propanoyl-3, 5diphenyl-4, 5-dihydro- $(1 \mathrm{H})$-pyrazole derivatives 55 and assayed as inhibitors of MAO-A and MAO-B isoforms.

These showed inhibitory activity with micromolar values and MAO-A selectivity and found to be useful as co-adjuvants in the treatment of Parkinson's disease (PD) and Alzhei-mer'sdisease.

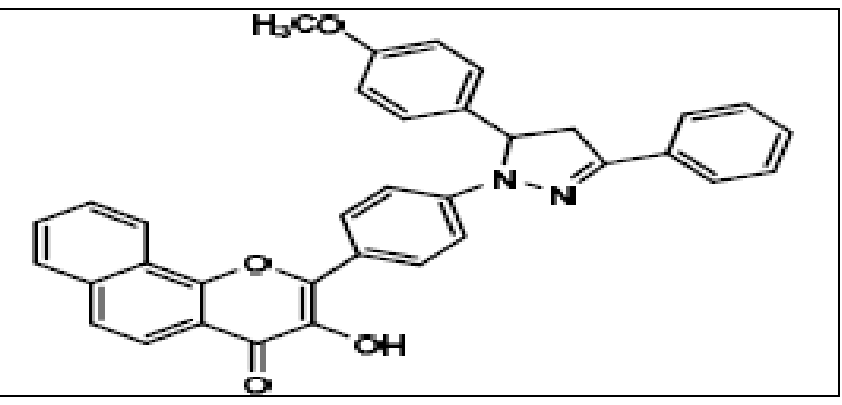

FIG. 61B: COMPOUND 61B

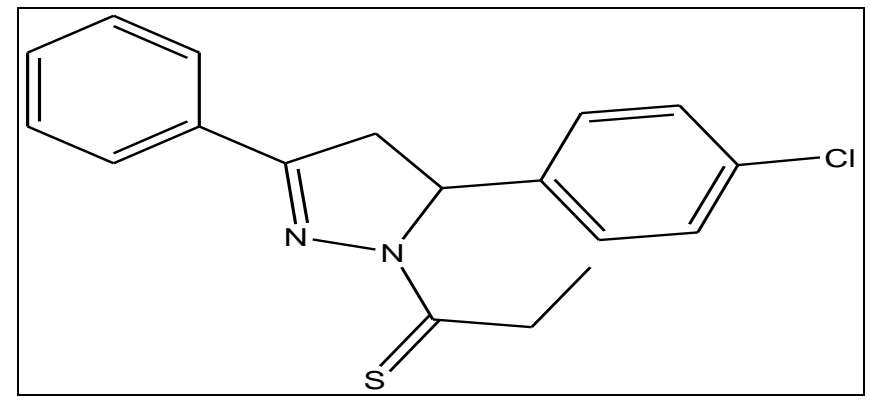

Photoluminescence (PL) activity: Wang et al ${ }^{51}$ synthesized 5 - (9 - Anthryl) - 3 - (4 - nitrophenyl)1-phenyl - 2-pyrazoline (ANPP) ${ }^{49}$ and screened its photoluminescence property.

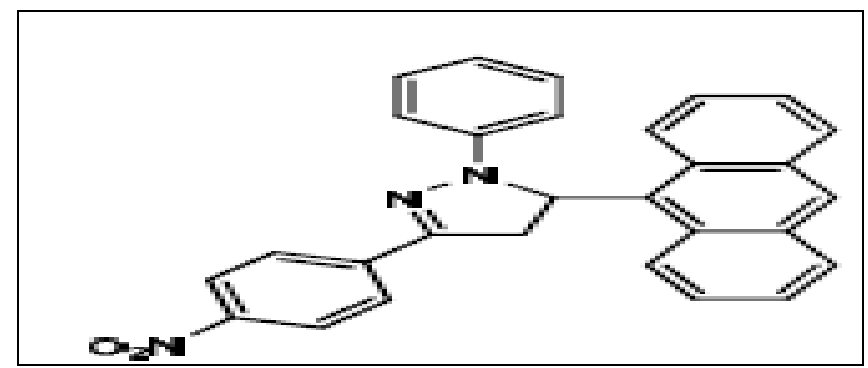

RESULTS AND DISCUSSION: In the present review, interest is focused on the profile of various pharmacological activities pyrazoline and its derivatives. Many scientists have synthesized novel pyrazoline derivatives. They have characterized the synthesized compounds by thin-layer chromatographic technique and analyzed the spectrum by IR, NMR, Mass spectra. Some compounds had been synthesized by the microwave method of synthesis, which is more convenient than the normal method 
of synthesis. The different biological activities were evaluated by in-vitro and in-vivo methods. In the present literature, it is seen that pyrazoline derivatives have been found to possess considerable biological activities, which stimulated the research activity in this field. Pyrazoline derivatives have prominent effects, such as antimicrobial, antimycobacterial, antifungal, antiamoebic, anti-inflammatory, analgesic, antidepressant, and anticancer activities. The neurotoxicity study reveals that the synthesized pyrazoline derivatives have zero toxicity. It is one of the tools for the design of some novel pyrazoline derivatives. The pharmacokinetic study includes the \% oral absorption, CNS activity etc which are also more prominent in pyrazoline derivatives. Some of the pyrazoline derivatives were also patented.

CONCLUSION: Pyrazoline is a unique template that is associated with several biological activities. This literature highlighted the research work of many researchers reported in the literature for different pharmacological activities on pyrazole and pyrazoline compounds synthesized. The review has presented comprehensive details of pyrazole and pyrazoline analogues, potent compounds reported for particular pharmacological activity. From the literature, we came to know that pyrazoline derivatives are having a broad spectrum of biological activities. Many new compounds have been made and patented, but still, there are new aspects to explore. So, it is concluded that the pyrazoline nucleus is one of the basic pharmacophores for the design of new drug development.

ACKNOWLEDGEMENT: The author is grateful to thank Dr. Biswajit Dash for guiding me.

CONFLICTS OF INTEREST: The author did not have any conflict of interest.

\section{REFERENCES:}

1. Eicher T: The chemistry of heterocycles: structure reactions, syntheses and applications. Wiley-VCH Second Edition 2003.

2. Nusrat BA and Rabiul I: Cytotoxicity study of pyrazole derivatives. Bangladesh Journalof Pharmacology 2007; 2: 81-87.

3. Rahman A and Siddiqui AA: Pyrazoline derivative: A Worthy Insight into the recent advances and potential pharmacological activities. International Journal of
Pharmaceutical Sciences and Drug Research 2010; 2(3): 165-75.

4. Eisinger J, Boens $\mathrm{N}$ and Flores J: Fluorescence polarization study of human erythrocyte membranes with 1-phenyl-3-(2-naphthyl)-2- pyrazoline as orientational probe. Biochimcaet Biophysica Acta 1981; 646: 334-43.

5. Li JF, Guan B, Li DX and Dong C: Study on the fluorescence properties of a new intramolecular charge transfer compound 1,5- diphenyl-3-(N-ethylcarbazole-3yl)-2-pyrazoline. Spectrochimica Acta Part A: Molecular and biomolecular Spectroscopy 2007; 68: 404-08.

6. Bai G, Li J, Li D, Dong C, Han X and Lin P: Synthesis and spectrum characteristic of four new organic fluorescent dyes of pyrazoline compounds. Dyesand Pigments 2007; 75: 93-98.

7. Lu Z, Jiang Q, Zhu W, Xie M, Hou Y, Chen X and Wang $\mathrm{Z}$ : Novel pyrazoline derivative used as light emitter in blue organic electroluminescent devices. Synthetic Metals 2000; 111: 465-68.

8. Evans NA, Rivett DE and Wilshire JFK: The chemical and photochemical properties of some 1, 3-diphenyl-2pyrazolines. Australian Journal of Chemistry 2005; 27: 2267-74.

9. ElShora AI: Crystal and molecular structure of 3hydrazino-1-hydrazinothio-carbonyl pyrazoline (TNT3). Egyptian Journal of Science 2000; 23: 251-54.

10. Li JT, Zhang XH and Lin ZP: An improved synthesis of 1, 3, 5-triaryl-2-pyrazolines in acetic acid aqueous solution under ultrasound irradiation. Beilstein Journal of Organic Chemistry 2007; 3: 1860-97.

11. Kelekci NG, Koyunoglu S, Yabanoglu S, Yelekci K, Ozgen O, Ucar G, Erol K, Kendi E and Yesilada A: New pyrazoline bearing 4-(3H)-quinazolinone inhibitors of monoamine oxidase: Synthesis,biological evaluation and structural determinants of MAO-A and MAO-B selectivity. Bioorganic and Medicinal Chemistry 2008; 22: 23-25.

12. Havrylyuk D, Zimenkovsky B, Vasylenko O, Zaprutko L, Gzella A and Lesyk R: Synthesis of novel thiazolonebased compounds containing pyrazoline moiety and evaluation of their anticancer activity. European Journal of Medicinal Chemistry 2008; 42: 1-9.

13. Sobhia HR, Yaminib Y, Esrafili A and Adiba M: Extraction and determination of 2-pyrazoline derivatives using liquid phase microextraction based on solidification of floating organic drop. Journal of Pharmaceutical and Biomedical Analysis 2008; 45: 316-20.

14. Gosselin F, O'Shea PD, Webster RA, Reamer RA, Tillyer RD and Grabowski EJJ: Highly regioselective synthesis of 1-Aryl-3,4,5-substotuted pyrazoles. Synlett 2006; 3267-70.

15. Walker MC and Sander JWAS: The impact of new antiepileptic drugs on the prognosis of epilepsy: seizure freedom should be the ultimate goal. Neurology 1996; 46(4): 912-14.

16. Ahmed MS, Kobayashi MK and Mori A: One-pot construction of pyrazoles and with palladium catalyzed four-component coupling. Organic Letter 2005; 7(20): 4487-89.

17. Powers DG, Casebier DS, Fokas D and Ryan WJ: Automated parallel synthesis of chalcone-based screening libraries. Tetrahedron 1998; 54: 4085.

18. LevaiA: Synthesis of chlorinated 3, 5-diaryl-2-pyrazolines by the reaction of chlorochalcones with hydrazines. Arkivoc 2005; 344-52.

19. Husain K, Mohammad A and Azam A: Novel Pd (II) complexes of 1-N-substituted 3-phenyl-2-pyrazoline 
derivatives and evaluation of antiamoebic activity. European Journal of Medicinal Chemistry 2008; 43: 39-03.

20. Ramesh B and Sumana T: Synthesis and AntiInflammatoryActivity of Pyrazolines. European Journal of Chemistry 2010; 7(2): 514-16.

21. Ju Y and Varma RS: Aqueous N-Heterocyclization of primary amines and Hydrazines with Dihalides: Microwave-Assisted syntheses of N-Azacycloalkanes, Isoindole, Pyrazole, Pyrazolidine and Phthalazine derivatives. J of Organic Chemistry 2006; 71: 135-41.

22. Alex K,Tillack A, Schwarz N and Beller M: Zinccatalysed synthesis of Pyrazolines and Pyrazoles via hydrohydrazination. Organic Letters 2008; 10: 2377-79.

23. Mehta S,Waldo JP, Neuenswander B, Lushington GH and Larock RC: Solution-Phase Parallel Synthesis of a Multisubstituted Cyclic Imidate Library. Organic Chemistry 2008; 73: 6666-70.

24. Cui SL,Wang $\mathbf{J}$ and Wang YG: Facile Access to Pyrazolines via Domino Reaction of the Huisgen Zwitterions with Aziridines. Organ Letter 2008; 10: 13-16.

25. Ohta $\mathrm{Y}$, Chiba $\mathrm{H}$, Oishi S, Fujii $\mathrm{N}$ and Ohno $\mathrm{H}$ : Construction of Nitrogen Heterocycles Bearing an Aminomethyl Group by Copper-Catalyzed Domino ThreeComponent Coupling-Cyclization. Journal of Organic Chemistry 2009; 74: 7052-58.

26. PalaskaE, AytemirM, Uzbay T and Erol D: Synthesis and antidepressant activities of some 3, 5-diphenyl-2pyrazolines. Europian J of Medi Chemi 2001; 36: 539-43.

27. Palaska E, Erol D and Demirdamar R: Synthesis and antidepressant activities of some 1,3,5-triphenyl-2pyrazolines. Europian J of Medici Chem 1996; 31: 43-47.

28. Prasad YR, Rao AL, Prasoona L and KMurali: Synthesis and antidepressant activity of some 1,3,5-triphenyl-2pyrazolines and 3-(2-hydroxynaphthalen-1-yl)-1,5diphenyl-2-pyrazolines. Bioorganic \& Medicinal Chemistry Letters 2005; 15: 5030-34.

29. Ozdemir Z, Kandilci HB, Gumusel B, Calis U and Bilgin AA: Synthesis and studies on antidepressant and anticonvulsant activities of some 3-(2-furyl)-pyrazoline derivatives. Europian Journal of Medicinal Chemistry 2007; 42: 373-79.

30. Sahu SK, Banerjee M, Samantray A, Behera C and Azam MA: Synthesis and antiviral evaluation of some new pyrazole and fused pyrazolopyrimidine derivatives. Tropical J of Pharmaceutic Research 2008; 7 (2): 961-68.

31. Kuecuekguezel SG, Rollas S, Erdeniz H, Kiraz M, Ekinci AC and Vidin A: Synthesis, characterization and pharmacological properties of some 4-arylhydrazono-2pyrazoline-5-one derivatives obtained from heterocyclic amines.Chemlnform 2000; 35(45): 761-71.

32. Singh SP, Chaudhari A, Barthwal JP and Parmar SS: Anticonvulsant activity and selective inhibition of nicotinamide adenine dinucleotide-dependent oxidations by $1,3, \quad 5$-trisubstituted pyrazolines. Journal of Pharmaceutical Sciences 1974; 63(12): 1948-50.

33. Mamolo MG, Zampieri D, Falagiani V, Vio L and Banfi E: Synthesis and antimycobacterial activity of 5-aryl-1isonicotinoyl-3-(pyridin- 2-yl)-4,5-dihydro-1H-pyrazole derivatives. IIFarmaco 2001; 56: 593-99.

34. Ozdemir A and Asim ZG: Novel analogues of 2pyrazoline: Synthesis, characterization and antimycobacterial evaluation. Turkish Journal of Chemistry 2008; 32: 529-38.

35. Zampieri D, Mamolo MG, Laurini E, Scialino G, Banfi E and Vio L: Antifungal and antimycobacterial activity of 1(3,5-diaryl-4,5- dihydro-1H-pyrazol-4-yl)-1H-imidazole derivatives. Bioor \& Medic Chemistry 2008; 16: 4516-22.
36. Kini SG, Bhat AR, Bryant B, Williamson JS and Dayan FE: Synthesis,antitubercular activity and docking study of novel cyclic azole substituted diphenyl ether derivatives. European Journalof Medicinal Chemistry 2008; 41: 1-9.

37. Ali MA, Shaharyar $M$ and Siddiqui AA: Synthesis, structural activity relationship and anti-tubercular activity of novel pyrazoline derivatives. European Journalof Medicinal Chemistry 2007; 42: 268-75.

38. Babu VH, Manna SK, Sneha, Srinivasan KK and Bhatt GV: Synthesis and biological evaluation of 1, 3, 5trisubstituted pyrazolines bearing benzofuran. Indian Journal of Heterocyclic Chemistry 2004; 13: 253-56.

39. Azarifar D and Shaebanzadeh M: Synthesis and Characterization of New 3, 5-Dinaphthyl Substituted 2Pyrazolines and Study of Their Antimicrobial Activity. Molecules 2002; 7: 885-95.

40. Sridhar R, Perumal PJ, Etti S, Shanmugam G, Ponnuswamy MN, Prabavathy VR and Mathivanan N: Design, synthesis and anti-microbial activity of $1 \mathrm{H}$-prazole carboxylate. Bioor \& Med Chem Lett 2004; 14: 6035-40.

41. Bondock S, Fadaly W and Metwally MA: Synthesis and antimicrobial activity of some new thiazole, thiophene and pyrazole derivatives containing benzothiazole moiety. European J of Medicinal Chemistry 2010; 48(5): 561-73.

42. Radi S, Salhi S and Radi A: Synthesis and preliminary biological activity of some new pyrazole derivatives as acyclonucleoside analogues. Letters in Drug Design \& Discovery 2010; 7: 27-30.

43. Toman JEP, Goodman LS and Gilman A: The Pharmacological Basis of Therapeutics. Eds New York MacMillan 1956; 3: 217.

44. Ozdemir A, TuranZitouni G, Kaplancıklı ZA, Revial G and Guven K: Synthesis and antimicrobial activity of 1-(4aryl - 2 - thiazolyl) - 3-(2-thienyl)-5-aryl-2-pyrazoline derivatives. European Journalof Medicinal Chemistry 2007; 42: 403-09.

45. Wahab ABA, Aziz AHA and Ahmed EM: Synthesis and antimicrobial evaluation of 1-(benzofuran-2-yl)-4-nitro-3arylbutan-1-ones and 3-(benzofuran-2-yl)-4,5-dihydro-5aryl-1-[4-(aryl)-1,3-thiazol-2-yl]-1H-pyrazoles. European Journalof Medicinal Chemistry 2008; 43: 1-4.

46. Stirrett KL, Ferreras JA, Jayaprakash V, Sinha BN, Renc T and Quadri LEN: Small molecules with structural similarities to siderophores as novel antimicrobials against Mycobacterium tuberculosis and Yersinia pestis. Bioorga and Medicinal Chemistry Letters 2008; 18: 2662-68.

47. Abunada NM, Hassaneen HM, Kandile NG and Miqdad OA: Synthesis and biological activity of some new pyrazoline and pyrrolo [3, 4-c] pyrazole-4, 6-dione derivatives: Reaction of nitrilimines with some dipolarophiles, Molecules 2008; 13: 1011-24.

48. Bhatt AH, Parekh HH, Parikh KA and Parikh AR: Synthesis of pyrazolines and cyanopyridines as potential antimicrobial agents,Indian J of Chemist 2001; 40: 57-61.

49. Bansal E, Srivastava VK and Kumar A: Synthesis and anti-inflammatory activity of 1-acetyl-5-substituted aryl-3(b-aminonaphthyl)-2-pyrazolines and b-(substituted aminoethyl) amidonaphthalenes. Europian Journal of Medicinal Chemistry 2001; 36: 81-92.

50. Budakoti A, Abid M and Azam A: Syntheses, characterization and in vitro antiamoebic activity of new Pd(II) complexes with 1-Nsubstituted thiocarbamoyl-3,5diphenyl-2-pyrazoline derivatives. Europian Journal of Medicinal Chemistry2007; 42: 544-51.

51. Bhat AR, Athar F and Azam A: Bis-pyrazolines: Synthesis, characterization and antiamoebic activity as 
inhibitors of growth of Entamoeba histolytica. Europian Journal of Medicinal Chemistry 2009; 44: 426-31.

52. Burguete A, Pontiki E, Hadjipavlou-Litina D, Villar R, Vicente E, Solano B, Ancizu S, Pe'rez-Silanes S, Aldanaa I and Monge A: Synthesis and antiinflammatory/antioxidant activities of some new ring substituted 3-phenyl-1-(1,4-di-N-oxide quinoxaline-2yl)-2propen-1-one derivatives and of their 4,5-dihydro- $(1 \mathrm{H})$ pyrazole analouges. Bioorganic \& Medicinal chemistry 2006; 17(23): 6439-43.

53. AliMA, Yar MS, Kumar M and Pandian GS: Synthesis and antitubercular activity of substituted novel pyrazoline derivatives. Natural Product Research 2007; 21: 575-79.

54. Rathish IG, Javed K and Ahmad S: Synthesis and antiinflammatory activity of some new 1,3,5-trisubstituted pyrazolines bearing benzene sulphonamide.Europian Journal of Medicinal Chemistry 2009; 19: 255-58.

55. Amir M, Kumar $H$ and Khan SA: Synthesis and pharmacological evaluation of pyrazoline derivatives as new anti-inflammatory and analgesic agents. Bioorganic \& Medicinal Chemistry Letters 2008; 18: 918-22.

56. Barsoum FF and Girgis AS: Facile synthesis of bis (4,5dihydro-1Hpyrazole-1-carboxamides) and their thioanalogues of potential PGE2 inhibitory properties. Europian Journal of Medicinal Chemistry 2008; 15: B1-6.

57. Rani P, Srivastava VK, Kumar A: Synthesis and antiinflammatory activity of heterocyclic indole derivatives. Europian J of Medicinal Chemistry 2004; 39: 449-52.

58. Kelekc NG, Yabanoglu S, Kupeli E, Salgın U, Ozgen O, Ucar G, ErdemYesilada, Kendi E, Yesiladaf A and Bilgin AA: A new therapeutic approach in Alzheimer disease: Some novel pyrazole derivatives as dual MAO-B inhibitors and anti-inflammatory analgesics. Bioorganic \& Medicinal Chemistry 2007; 15: 5775-86.

59. Khode S, Maddi V, Aragade P, Palkar M, Ronad PK, Mamledesai S, Thippeswamy AHM and Satyanarayana D: Synthesis and pharmacological evaluation of a novel series of 5-(substituted) aryl-3-(3-coumarinyl)-1-phenyl-2pyrazolines as novel anti-inflammatory and analgesic agents. Europian J of Medicinal Chemistry 2008; 21: 1-7.

60. Shoman ME, Aziz AM, Aly OM, Farag HH and Morsy MA: Synthesis and investigation of anti-inflammatory activity and gastric ulcerogenicity of novel nitric oxidedonating pyrazoline derivatives. Europian Journal of Medicinal Chemistry 2008; 22: 1-9.

61. Kaplancikli ZA, Turan Zitouni G, Ozdemir A, Devrimcan $\mathrm{O}$ and Chevallet P: Synthesis and antinociceptive activities of some pyrazoline derivatives. Europian Journal of Medicinal Chemistry 2008; 17: 1-5.

62. Cheng LP, Zhu HL, Li HQ, Sun J and Zhou Y: Synthesis and biological evaluation of pyrazole derivatives containing thiourea skeleton as anticancer agents. Bioorganic \&Medicinal Chemistry 2010; 18: 4606-14.

63. Havrylyuk D, Zimenkovsky B, Vasylenko O, Zaprutko L, Gzella A and Lesyk R: Synthesis of novel thiazolonebased compoundscontaining pyrazoline moiety and evaluation of their anticancer activity. Europian Journal of Medicinal Chemistry 2008; 42: 1-9.

64. Bhat BA, Dhar KL, Puri SC, Saxena AK, Shanmugavel M and Qazi GN: Synthesis and biological evaluation of chalcones and their derived pyrazoles as potential cytotoxic agents. Bioorganic \& Medicinal Chemistry Letters 2005; 15: 3177-80.

65. Manna F, Chimenti F, Fioravanti R, Bolasco A, Secci D, Chimenti P, Ferlini C and Scambi G: Synthesis of some pyrazole derivatives and preliminary investigation of their affinity binding to P-glycoprotein. Bioorganic \& Medicinal Chemistry Letters 2005; 15: 4632-35.

66. TuranZG, Chevallet P, Kilic FS and Erolc K: Synthesis of some thiazolyl-pyrazoline derivatives and preliminary investigation of their hypotensive activity. Europian Journal of Medicinal Chemistry2000; 35: 635-41.

67. Bonesi M, Loizzo MR, Statti GA, Michel S, Tillequin F and Menichini: The synthesis and ACE inhibitory activity of chalcones and their pyrazole derivatives. Bioorganic \& Medicinal Chemistry Letters 2010; 20: 1990-93.

68. Jeong TS, Kim KS, An SJ, Cho KH, Lee S and Lee WS Novel 3, 5- diaryl pyrazolines as human acylCoA:cholesterol acyltransferase inhibitors. Bioorganic \& Medicinal Chemistry Letters 2004; 14: 2715-17.

69. Srivastava BK, Joharapurkar A and Raval S: Diaryl dihydropyrazole-3-carboxamides with significant in-vivo antiobesity activity related to $\mathrm{CB} 1$ receptor antagonism: Synthesis, biological evaluation, and molecular modeling in the homology model. Journal of Medicinal Chemistry 2007; 50: 5951-66.

70. Camacho ME, León $\mathrm{J}$ and Entrena A: 4,5-Dihydro-1Hpyrazole derivatives with inhibitory nNOS activity in rat brain: Synthesis and structure-activity relationships. Journal of Medicinal Chemistry 2004; 47: 5641-50.

71. Zhang X, Li X and Allan GF: Design, synthesis, and invivo SAR of a novel series of pyrazolines as potent selective androgen receptor modulators. Journal of Medicinal Chemistry 2007; 50: 3857-69.

72. Babu VH, Sridevi C, Joseph A and Srinivasan KK: Synthesis and biological evaluation of some novel pyrazolines. Indian J of Pharmac science 2008; 69: 470-73.

73. Svechkarev DA, Bukatich IV and Doroshenko AO: New 1, 3,5 - triphenyl - 2 - pyrazoline-containing 3-hydroxychromones as highly solvatofluoro chromicratiometric polarity probes. J of Phytochemistry and Photobiology A: Chemistry 2008; 200: 426-31.

How to cite this article:

Dash B and Karim S: Pyrazoline heterocyclic: a review. Int J Pharm Sci \& Res 2021; 12(5): 2570-88. doi: 10.13040/IJPSR.09758232.12(5).2570-88.

All $\odot 2013$ are reserved by the International Journal of Pharmaceutical Sciences and Research. This Journal licensed under a Creative Commons Attribution-NonCommercial-ShareAlike 3.0 Unported License.

This article can be downloaded to Android OS-based mobile. Scan QR Code using Code/Bar Scanner from your mobile. (Scanners are available on Google Playstore) 